\title{
Computational Investigation on the Biomechanical Responses of the Osteocytes to the Compressive Stimulus: A Poroelastic Model
}

\author{
Liping Wang $\mathbb{D}^{1}{ }^{1}$ Jianghui Dong, $^{2}$ and Cory J. Xian $\mathbb{D}^{1}$ \\ ${ }^{1}$ Sansom Institute for Health Research, School of Pharmacy and Medical Sciences, University of South Australia, \\ Adelaide, SA 5001, Australia \\ ${ }^{2}$ School of Natural and Built Environments, University of South Australia, Adelaide, SA 5095, Australia \\ Correspondence should be addressed to Cory J. Xian; cory.xian@unisa.edu.au
}

Received 29 August 2017; Revised 2 December 2017; Accepted 19 December 2017; Published 18 January 2018

Academic Editor: Jiang Du

Copyright (C) 2018 Liping Wang et al. This is an open access article distributed under the Creative Commons Attribution License, which permits unrestricted use, distribution, and reproduction in any medium, provided the original work is properly cited.

\begin{abstract}
Osteocytes, the major type of bone cells embedded in the bone matrix and surrounded by the lacunar and canalicular system, can serve as biomechanosensors and biomechanotranducers of the bone. Theoretical analytical methods have been employed to investigate the biomechanical responses of osteocytes in vivo; the poroelastic properties have not been taken into consideration in the three-dimensional (3D) finite element model. In this study, a 3D poroelastic idealized finite element model was developed and was used to predict biomechanical behaviours (maximal principal strain, pore pressure, and fluid velocity) of the osteocytelacunar-canalicular system under 150-, 1000-, 3000-, and 5000-microstrain compressive loads, respectively, representing disuse, physiological, overuse, and pathological overload loading stimuli. The highest local strain, pore pressure, and fluid velocity were found to be highest at the proximal region of cell processes. These data suggest that the strain, pore pressure, and fluid velocity of the osteocyte-lacunar-canalicular system increase with the global loading and that the poroelastic material property affects the biomechanical responses to the compressive stimulus. This new model can be used to predict the mechanobiological behaviours of osteocytes under the four different compressive loadings and may provide an insight into the mechanisms of mechanosensation and mechanotransduction of the bone.
\end{abstract}

\section{Introduction}

Bone is a dynamic biological structure that can adapt to its mechanical environment by changing its structure $[1,2]$. The mechanical stimulation has now been recognized vital for regulating bone remodelling processes of bone formation (by bone-forming cells osteoblasts) and resorption (by boneresorptive cells osteoclasts) and thus bone microstructure, bone mass, and bone strength [3]. Osteocytes are seen as the main candidates for mechanosensory effects of the bone, which are the most numerous bone cells (making up about $90-95 \%[4,5]$ of all bone cells, with osteoblasts and osteoclasts together only making up a total of up to $6 \%$ [6]).

Osteocytes are known to regulate bone remodelling and are located within their lacunae surrounded by the perilacunar matrix (PCM) embedded in the bone matrix (extracellular matrix or ECM). Osteocytes are connected to each other with slender cell processes located within small tubes called the canaliculi within the bone matrix. It is believed that, through this osteocyte cell body-cell process-lacunar-canalicular system, the osteocytes are the mechanosensors/mechanotranducers in bones, which can sense the mechanical loadings and transduce them into biochemical signals regulating bone remodelling [7-11].

To investigate bone tissue mechanosensing/mechanotransduction and biomechanical behaviours of osteocytes, a number of researchers have studied the osteocyte-lacunarcanalicular system by theoretical analytical models. The mathematical model has been a good tool to explain the phenomenon of mechanotransduction in the lacunar-canalicular system [12], which is well accepted to be induced by flow movement-like fluid shear stresses [13-19]. Combined with microfocus computer tomography (mCT), the finite element (FE) modeling can be a biomechanical analysis tool to study bone [20]. In addition, the FE method can be used to simulate blood flow, regeneration processes, bone remodeling 
process, and heat transfer and evaluate bone strength [21, 22]. McCreadie and Hollister (1997) were the first researchers to study the mechanical behaviours of lacunae and osteocytes by using an idealized 3D linearly isotropic material FE model [23]. Bonivtch et al. (2007) analysed the microstructural responses of the osteocyte lacuna by using a parametric linearly isotropic material FE model [24]. Sanz-Herrera et al. (2008) developed the FE and the Voxel-FE models at the macroscopic and microscopic scales [25]. More recently, with the development of computer and FE analysis software, the FE analysis has been widely applied to investigate the biomechanical behaviours of osteocytes [26-29]. 3D linearly isotropic material FE models of osteocytes have been developed including an idealized model and biorealistic (confocal image-derived) model [26]. A linearly isotropic material 3D biorealistic osteocyte FE model was created based on synchrotron X-ray phase nanotomography [30]. Strain amplification analysis was conducted on an osteocyte under static and cyclic loading using an idealized linearly isotropic material 3D FE model [28]. Based on quasi-3-dimensional (quasi-3D) cell microscopy, a fluid-structure interaction FE method was used to study viscoelastic property [29]. Thus, the FE model analysis is an effective alternative method for the in vitro biomechanical studies [22].

Since nutrients and exchanges of metabolic products or biochemical signals of osteocytes depend on the movement of interstitial fluid [31], basically, nutrients are transported by both fluid flow and diffusion within the bone [32-34]. Reich et al. (1990) [35] and Reich and Frangos (1991) [36] were the first to conduct fluid flow studies on bone cells in culture, and they found that osteoblasts and endothelial cells had similar responses to fluid shear stress excitation. Small molecules (e.g., amino acids) can be diffusively transported alone to the osteocytes [37]. The solute transport occurred through the lacunar-canalicular system under cyclic loading, when the concentrations were different in the lacunar flow between the inward and outward [33]. Goulet et al. [32] used a homogeneous model and a vascularized model to demonstrate the bulk fluid movement and fluid exchange between the canals and the lacunocanalicular porosity. The process of the diffusional mixing was very fast and the numerous osteocyte lacunae are used as mixing chambers [17]. Osteocytes were proposed to be stimulated by relatively small fluid shear stresses acting on the membranes of the osteocytes [14]. In addition, since the passage of interstitial pore fluid adjacent to dendritic cell structure occurs in the porosity of the bone hierarchical microstructure, interaction of fluid and the osteocyte-lacunar-canalicular system has been regarded to play an important role in bone tissue mechanosensing and mechanotransduction. Thus, it has been recognized that understanding the actual physics of flows in bone is important for the analyses of bone remodelling and the bone hierarchical microstructure [38].

Poroelasticity is a well-developed theory for investigating the interaction of fluid and solid phases in a fluid-saturated porous medium [39-41], which has been an important means applied in research into bone and the osteocyte-lacunarcanalicular system [31, 42-45]. Based on the theory of poroelasticity, the poroelastic properties include drained shear modulus, drained and undrained Poisson's and Skempton's coefficient, and permeability coefficient [39, 46, 47]. This poroelastic theory was the first model used to study the smallscale fluid mechanics within the lacunar-canalicular porosity using Brinkman's equation (Darcy's law and Stokes equation). The poroelastic properties should be taken into account in the study of the osteocyte-lacunar-canalicular system [48, 49]. A computational model was developed to explore load-induced fluid flow in bone as a mechanotransduction mechanism under physiologically realistic loading with different frequencies [50]. Subsequently, a 2D anisotropic poroelastic model was used to study the local fluid flow characteristics in the vicinity of a single lacuna [19]. More recently, Nguyen et al. studied the mechanical behaviours of one single chondrocyte by using poroviscohyperelastic model [45].

However, the material properties of the models in some of the previous studies $[23,24,26,51]$ were assumed solid, in which the fluid or the interaction between fluid and solid matrix was ignored. Although the poroelastic properties were considered in some studies, these models were theoretical models $[42,47,52]$ or $2 \mathrm{D}$ FE models [19]. In addition, while foregoing FE models had focused on the physiological compressive loading, there has been little attempt reported investigating/comparing the effects of disuse (150 microstrains), physiological (1000 microstrains), overuse (3000 microstrains), and pathological overload (5000 microstrains) compressive loads [53, 54] on the osteocyte-lacunar-canalicular system using FE model analyses. In the current study, an idealized $3 \mathrm{D}$ poroelastic FE model was developed to investigate the biomechanical responses of the osteocyte-lacunar-canalicular system when subjected to four different compressive loads. Since it has been stated that, in general, the disuse load was under $200 \mu \varepsilon$, the physiological load was between 200 and $2500 \mu \varepsilon$, and the overuse loading range was $2500-5000 \mu \varepsilon$ [53], consistently, the osteocyte-lacunar-canalicular system FE model in the current study was selected to be under the global compressive loads of 150 microstrains (disuse), 1000 microstrains (physiological), 3000 microstrains (overuse), and 5000 microstrains (pathological overload), respectively. Under these loads, the following three analyses were made: (1) the distributions of the maximum principal strains; (2) the distributions of the maximum pore pressures; and (3) the maximum fluid velocities of the FE model.

\section{Materials and Methods}

2.1. Geometry and a 3D Model of the Idealized OsteocyteLacunar-Canalicular System. The osteocyte-lacunar-canalicular system was idealized as a 3D structure (Figure 1). The osteocyte lacuna was described as a triaxial ellipsoid, which can be expressed as follows [55].

$$
\left(\frac{x}{l}\right)^{2}+\left(\frac{y}{m}\right)^{2}+\left(\frac{z}{n}\right)^{2}=1
$$

where $l, m$, and $n$ are the semiaxes of the osteocyte lacuna in $x, y$, and $z$ directions, respectively. $x, y$, and $z$ are the minor, major, and intermediate axes of the osteocyte lacuna 


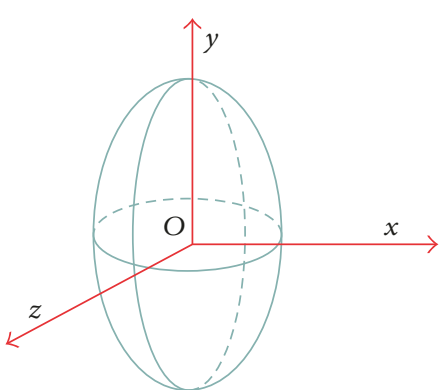

(a)

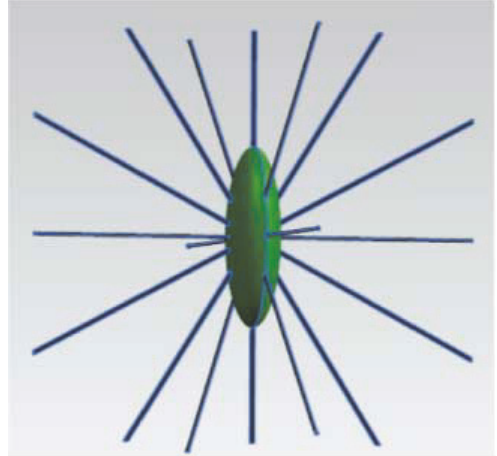

(b)

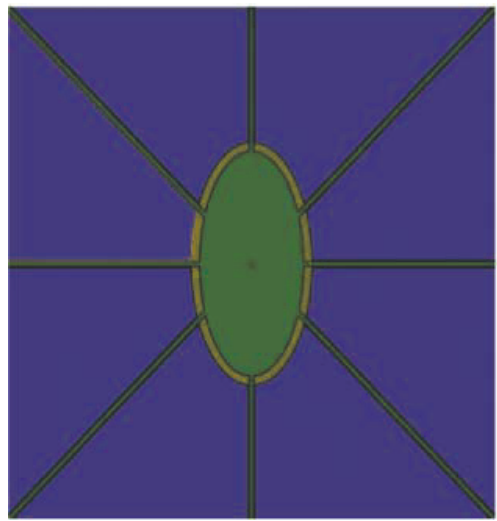

(c)

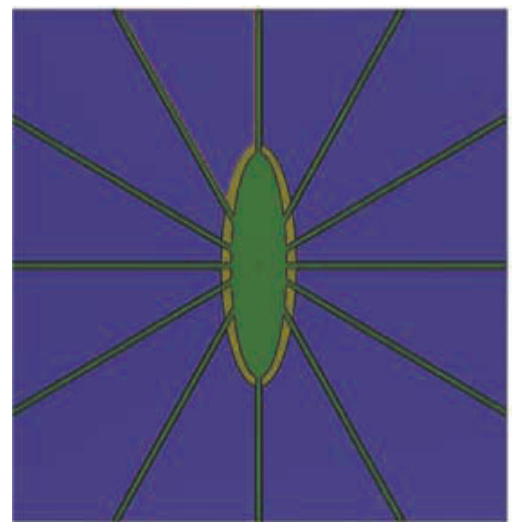

(d)

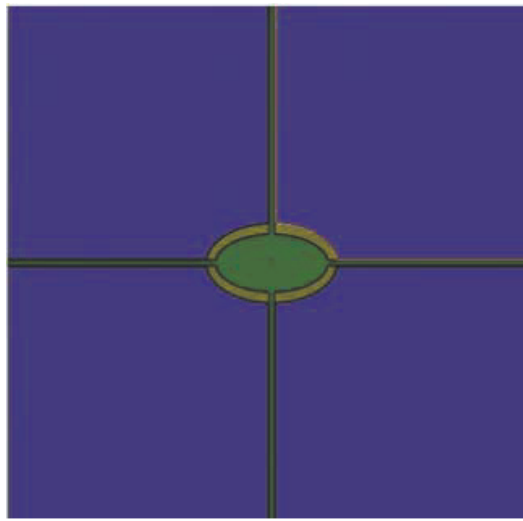

(e)

FIGURE 1: 3-dimensional schematic representations of an idealized osteocyte-lacunar-canalicular system. (a) A schematic diagram of an osteocyte lacuna, where $z$ is the intermediate axis, $y$ the major axis, and $x$ the minor axis of the lacuna in the local coordinate system. Schematic diagrams of osteocyte lacuna and canaliculi, showing (b) osteocyte cell body (green) with processes (blue); (c) in $x$ - $y$ plane; (d) in $z$ - $y$ plane; and (e) in $x-z$ plane.

TABLE 1: Element numbers and element types of the finite element model of the osteocyte-lacunar-canalicular system.

\begin{tabular}{lcc}
\hline Components & Number of elements & Element type \\
\hline ECM & 77480 & Solid \\
$\begin{array}{l}\text { PCM with canaliculi } \\
\begin{array}{l}\text { Osteocyte cell body and } \\
\text { processes }\end{array}\end{array}$ & 7183 & Solid \\
\hline Total & 23205 & Solid \\
\hline
\end{tabular}

ECM: extracellular matrix; PCM: perilacunar matrix.

in the local coordinate system, respectively (Figure 1(a)). The idealized model is comprised of a number of parts, that is, ECM, PCM, osteocyte cell body, canaliculi, and cell processes [28] (Figures 1 and 2 and Table 1).

The side length of each direction of the ECM cube is $43 \mu \mathrm{m}$ for human [55] and is the outermost layer of the system, which was modeled as an external solid layer, consisting of 77480 eight-node solid brick elements (Figure 2 and Table 1).
The middle layer of the system is the PCM with canaliculi that separates the ECM and the osteocyte cell body [2] (Figure 3). Here, it was modeled by two parts, namely, the PCM, $\sim 0.5-1 \mu \mathrm{m}$ thick layer [56], and the canaliculi, straight cylindrical channels with a diameter of $0.25 \mu \mathrm{m}[1,57]$. Here, both the PCM and canaliculi are solid and consist of 7183 eight-node brick elements in total (Table 1).

In this study, the simulations were conducted using the software ABAQUS 6.12 (SIMULIA, Providence, RI, USA) to assume fully saturated media. In the simulations, only $1 / 8$ symmetry model was applied in the whole FE analyses because the model is symmetrical (Figure 2). Also, the elements are eight-node C3D8R elements.

\subsection{Properties of Poroelastic Materials Applied in the Osteo-} cyte-Lacunar-Canalicular System. The material properties (isotropic material) used to represent the osteocyte-lacunarcanalicular system are listed in Table 2. In this study, to develop the model, ECM, PCM, and osteocyte cell body were assumed to be poroelastic materials. In the poroelastic constitutive law, the total stress $\left(\sigma_{T}\right)$ acting at a point results from the combination of an effective stress $\left(\sigma_{E}\right)$ and a pore 


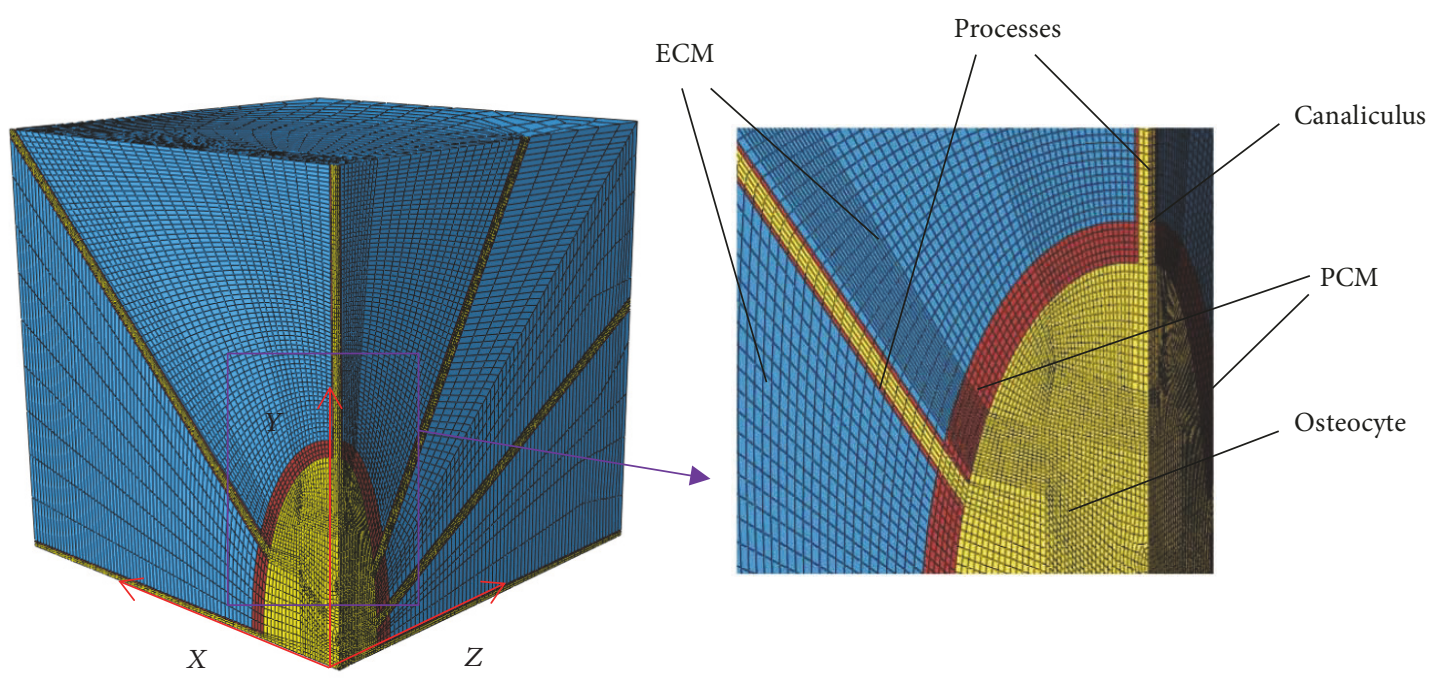

Figure 2: One-eighth symmetry model applied in the 3-dimensional finite element meshing analyses of the idealized osteocyte-lacunarcanalicular system, showing the geometric locations of extracellular matrix (ECM), perilacunar matrix (PCM), osteocyte cell body, canaliculi, and cell processes.

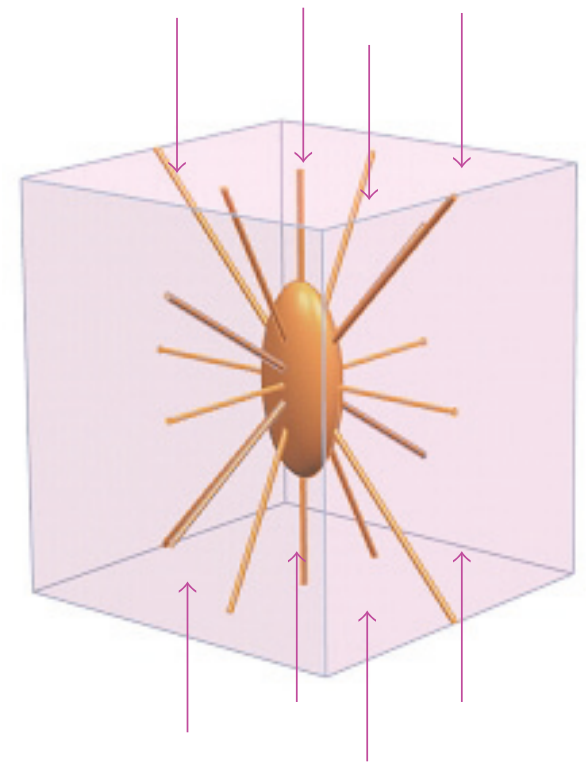

(a)

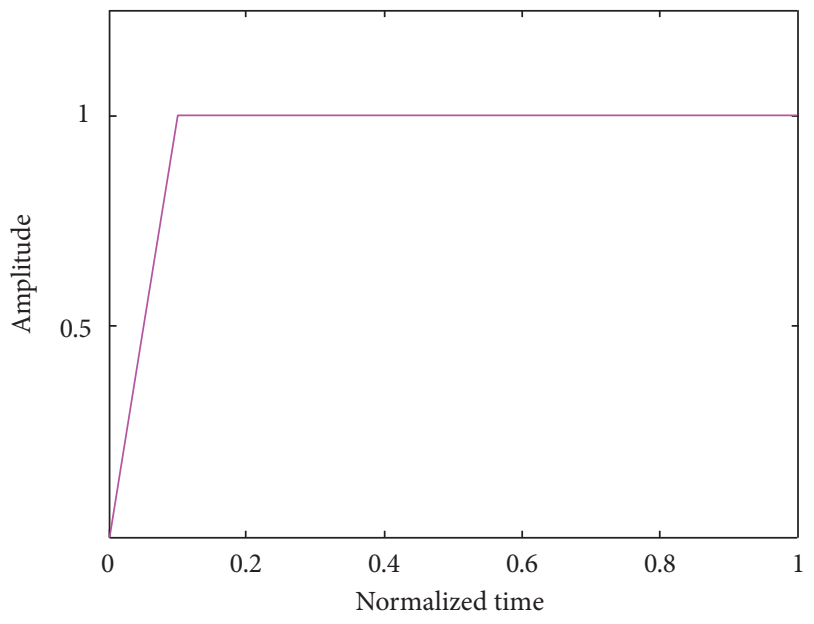

(b)

FIGURE 3: Conditions of compressive loading for the osteocyte-lacunar-canalicular system finite element model. (a) Uniaxial compressive loading; (b) loading mode.

TABle 2: Properties of the poroelastic materials applied in the finite element model of the osteocyte-lacunar-canalicular system.

\begin{tabular}{|c|c|c|c|c|}
\hline Components of osteocyte lacunae & Young's module & Poisson's ratio & Permeability $k_{0}\left(\mathrm{~m}^{2}\right)$ & Void ratio $e_{0}$ \\
\hline ECM & 11 GP [19] & 0.38 [19] & $1.0 \times 10^{-20}[58]$ & $0.053[58]$ \\
\hline PCM with canaliculi & $40 \mathrm{kPa}[59,60]$ & $0.4[59,60]$ & $4 \times 10^{-20}[59,60]$ & $4[59,60]$ \\
\hline Osteocyte cell body and processes & $3.1 \mathrm{kPa}[45,61]$ & $0.35[45,61]$ & $0.6 \times 10^{-19}[45,61]$ & $4.88[59,60]$ \\
\hline
\end{tabular}

ECM: extracellular matrix; PCM: perilacunar matrix. 
pressure $(p)$, respectively, carried out by the solid matrix and the fluid phase. Their relationship is shown in (2). In addition, the poroelastic formulation is based on the field variables $u$ (solid displacement) and $p$ (pore pressure) in ABAQUS (3).

$$
\begin{aligned}
\sigma_{T} & =\sigma_{E}-p I \\
\nabla u+\nabla \vec{q} & =0,
\end{aligned}
$$

where $I$ is the unit tensor, $\nabla$ represents gradient, and $\vec{q}$ is fluid mass flow.

The fluid mass flow $\vec{q}$ is relative to the pore pressure and can be computed according to Darcy's generalised law for flow through porous media, and the calculated formula can be expressed as follows.

$$
\vec{q}=-k \nabla p
$$

The fluid flow can also be expressed as follows:

$$
\vec{q}=\vec{v} \times n_{f}
$$

where $k$ is the permeability (which is assumed isotropic in this study), $\nabla p$ is the gradient of pore pressure, $\vec{v}$ is fluid velocity, and $n_{f}$ is fluid volume fraction (porosity).

Material parameters involved in the poroelastic formulation are Young's modulus $(E)$, Poisson ratio $(v)$, porosity $\left(n_{f}\right)$ [which is related to the void ratio $(e)$ and can be expressed as (6) and (7)], and permeability ( $k$, unit of $\left.\mathrm{m}^{2}\right)$. The straindependent permeability with the exponential constitutive law has been developed [64-66]. The permeability $k$ is assumed as the function of void ratio and may be expressed as (8) [67]. This function can be implemented in ABAQUS software package.

$$
\begin{aligned}
n_{f} & =\frac{V_{\text {fluid }}}{V_{\text {fluid }}+V_{\text {solid }}}=\frac{V_{\text {fluid }}}{V_{\text {total }}}=\frac{e}{1+e} \\
e & =\frac{V_{\text {fluid }}}{V_{\text {solid }}}=\frac{V_{\text {fluid }}}{V_{\text {total }}-V_{\text {solid }}}=\frac{n_{f}}{1-n_{f}} \\
k & =k_{0}\left[\frac{e\left(1+e_{0}\right)}{e_{0}(1+e)}\right]^{2} \exp \left[M\left(\frac{1+e}{1+e_{0}}-1\right)\right],
\end{aligned}
$$

where $V_{\text {fluid }}$ is the volume of void-space (such as fluids), $V_{\text {solid }}$ is the volume of solids, $V_{\text {total }}$ is the total or bulk volume, $e$ is void ratio, $k_{0}$ is the initial permeability, $e_{0}$ is the initial void ratio, and $M$ is a constant and needs to be determined [68].

2.3. Boundary and Loading Conditions. In order to investigate the biomechanical behaviours of the osteocyte-lacunarcanalicular system, the compressive loadings were applied to the 3D FE model. In this study, the displacements were used as loadings rather than the forces. In the current study, the uniaxial ramped static loading was applied on the model.

Uniaxial compressive loads were applied in the long bone axis (Figure 3), with global displacement loads of compressive loads applied, respectively, at 150 microstrains (disuse), 1000 microstrains (physiological), 3000 microstrains (overuse),
TABLE 3: Strain amplification factor comparisons between this study and previous studies.

\begin{tabular}{lcc}
\hline Sources & Method & $\begin{array}{c}\text { Strain } \\
\text { amplification } \\
\text { factor }\end{array}$ \\
\hline Present method & FEM (poroelastic) & 4.3 \\
{$[24]$} & FEM (linearly isotropic) & 3.14 \\
{$[62,63]$} & In vitro measurement & $3.99-11.43$ \\
\hline
\end{tabular}

and 5000 microstrains (pathological overload) [53, 62]. In order to prevent any relative movements in all simulations and to ensure the PCM attaching to the osteocyte and ECM, they were assumed being bonded perfectly. Thus, the displacement should be the same for the interface surfaces. ECM, PCM and canaliculi, and osteocyte cell body and processes were assumed being bonded perfectly. Distributions of the maximum principal strains of the osteocyte-lacunarcanalicular system FE model were simulated under these different loads.

To prevent rigid body motion, the symmetrical boundary conditions were applied to the nodes on the opposing faces of the applied displacement loading, and only $1 / 8$ of the symmetry model was used in the FE analyses. Furthermore, the initial fluid pore pressure was assumed to be zero and imposed on the external surfaces of the model due to the lack of osmotic pressure in the osteocyte-lacunar-canalicular system [59].

\section{Results}

3.1. Validations of the Osteocyte-Lacunar-Canalicular System FE Model. Distributions of the maximum principal strains of the osteocyte-lacunar-canalicular system FE model were predicted under global compressive loads of 150 microstrains (disuse), 1000 microstrains (physiological), 3000 microstrains (overuse), and 5000 microstrains (pathological overload), respectively. The maximum principal strains of the FE model were found to be $\sim 633,4272,12820$, and 21528 microstrains, respectively. The strain distribution of the model under the 1000-microstrain compressive loading is shown in Figure 4. The peak amplitudes of the cellular processes were found higher than those of the ECM, PCM, and the cell body (Figure 4). Moreover, the strain amplification factor of simulation was $\sim 4.3$ (Table 3 ). These findings are in agreement with those of the previous studies $[2,24,63$, 69], where the maximum strain amplification factors were measured to be $\sim 7.5$ in the in vitro measurement. While 7.5 was the maximum value of one of the many tested osteocytes, the average strain amplification factor was $\sim 4[63,69]$.

The maximum pore pressures on the cell and processes were $8.98,74.24,175.9$, and $285.7 \mathrm{kPa}$ when the model was subjected to global compressive loads of 150, 1000, 3000, and 5000 microstrains, respectively. Figure 5 shows the pore pressure and distribution results of the FE model when under 1000-microstrain compression loading. As shown, the predicted maximum pore pressure of the model occurs at 0.1 


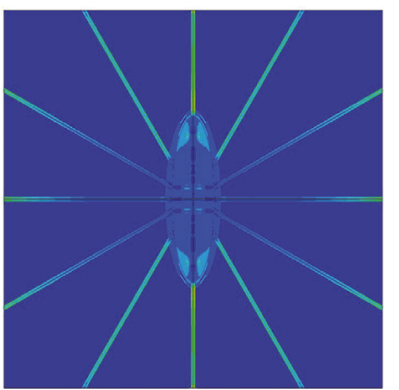

(a)

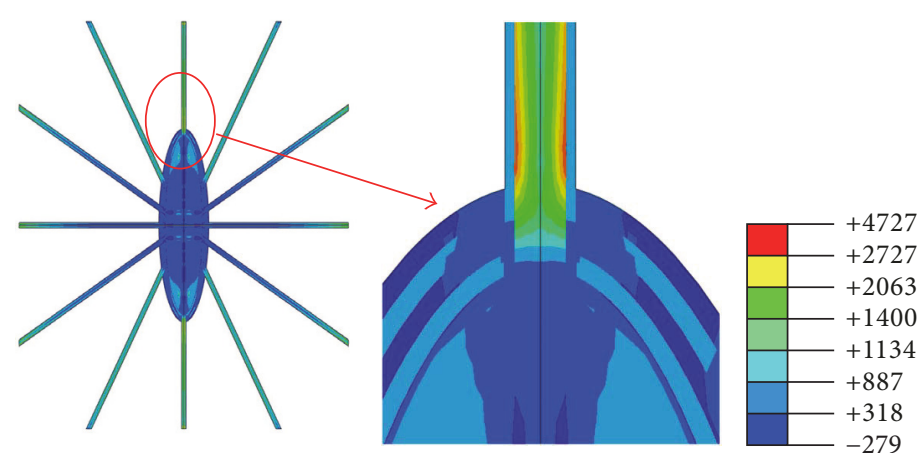

(b)

Figure 4: Strain distributions of finite element model under 1000-microstrain global loading. (a) Perilacunar matrix and osteocyte; (b) extracellular matrix.

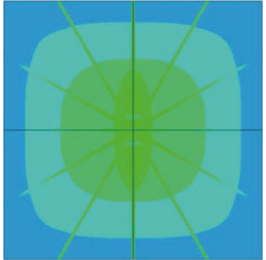

$t=0.02 T$

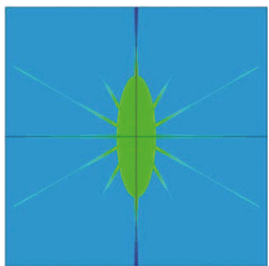

$t=0.4 T$

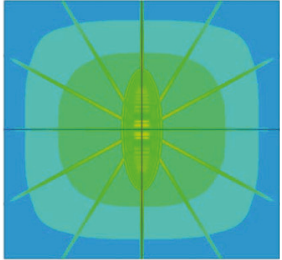

$t=0.1 T$

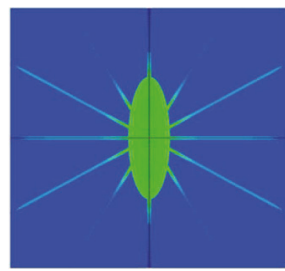

$t=0.6 T$

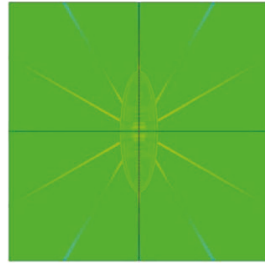

$t=0.12 T$

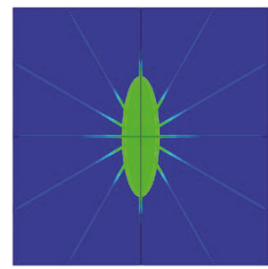

$t=0.8 T$

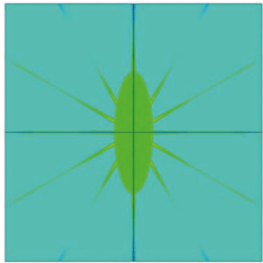

$t=0.2 T$

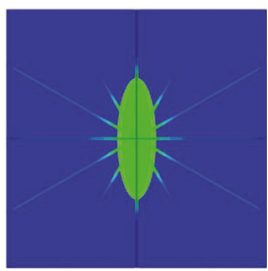

$t=T$

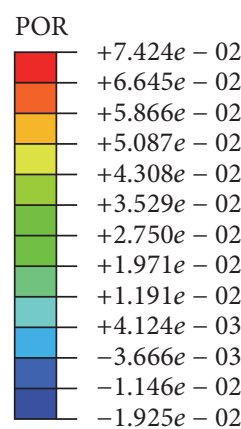

(a)

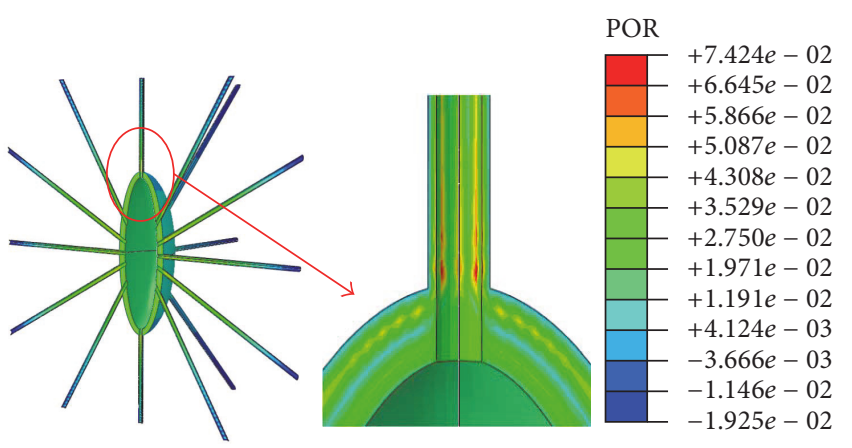

(b)

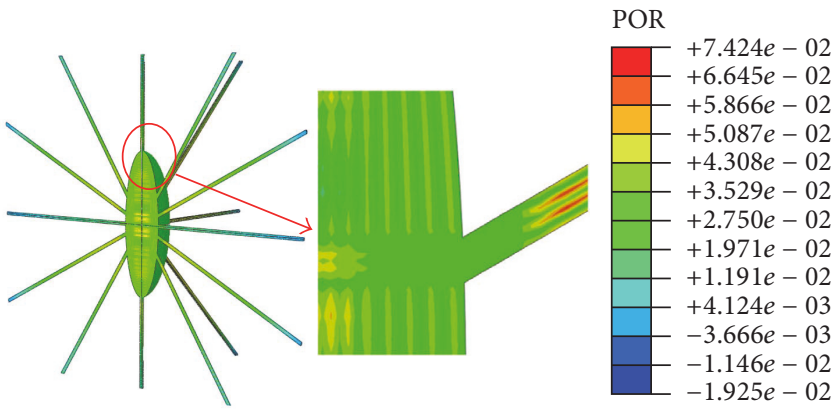

(c)

FIGURE 5: Pore pressure distributions of the osteocyte-lacunar-canalicular system under 1000-microstrain compressive loading. (a) The maximum pore pressure when $t=0.02,0.1,0.12,0.2,0.4,0.6,0.8$, or $1.0 T$ (total period of loading); (b) pore pressure distributions at canaliculi and perilacunar matrix when $t=0.1 T$; (c) pore pressure distributions in osteocyte and processes when $t=0.1 T$.

of the total period of loading $(0.1 T)$, and the maximum pore pressure is located at the junction areas of canaliculi, PCM, and processes.

Previously, the maximum pore pressure of the cortical bone was found to be up to $250 \mathrm{kPa}$ under $1 \mathrm{MPa}$ uniaxial stress [50], and the maximum hydraulic pressure of the lacunar-canalicular system was up to $5 \mathrm{MPa}$ when an osteon was subjected to $1 \mathrm{~Hz} 1000$ microstrain compression [15]. Thus, the predicted pore pressure values of our model (i.e., $8.98,74.24,175.9$, and $285.7 \mathrm{kPa}$ for the compressive loads of $150,1000,3000$, and 5000 microstrains, respectively) are within the range of predicted values of these previous studies. 

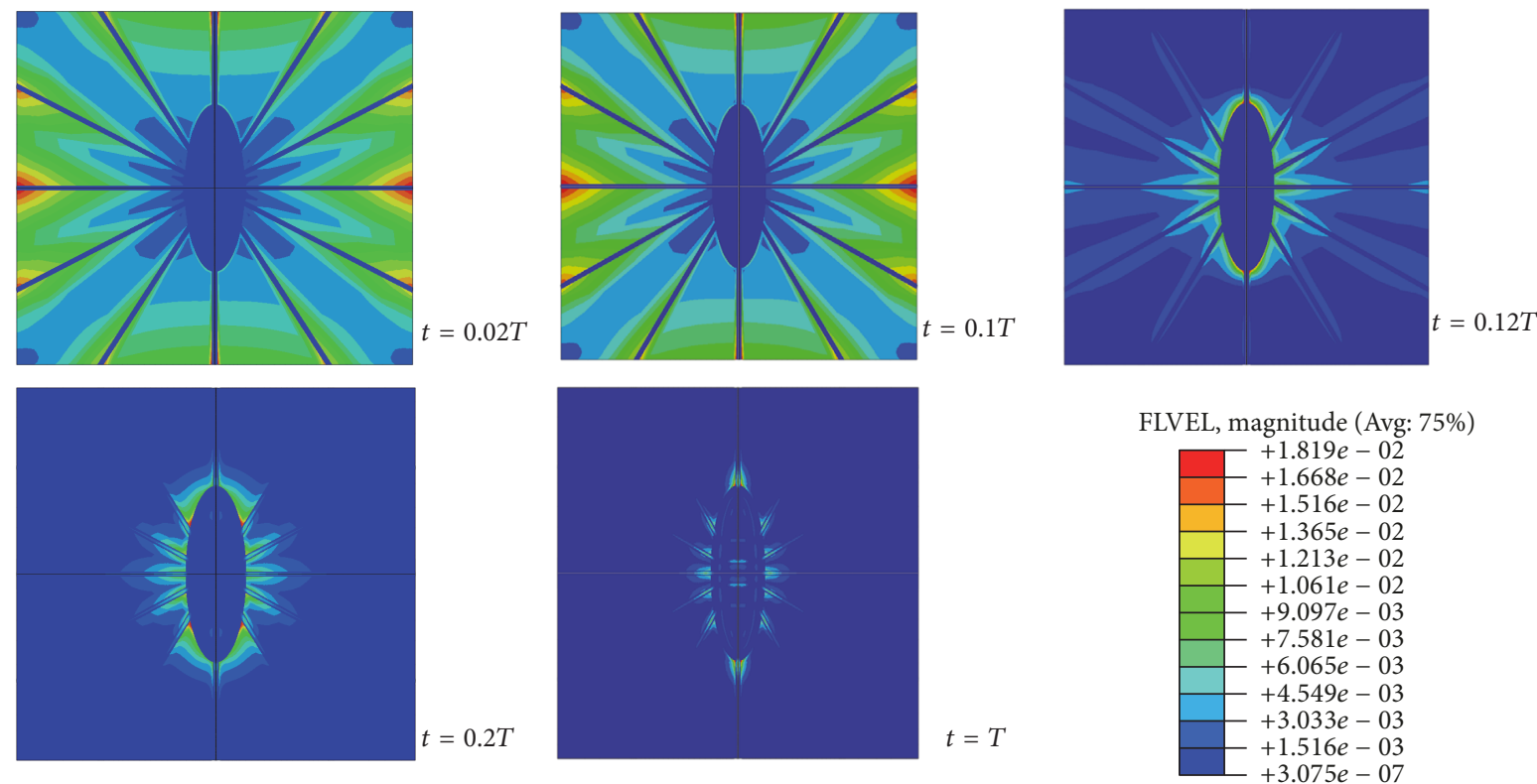

(a)

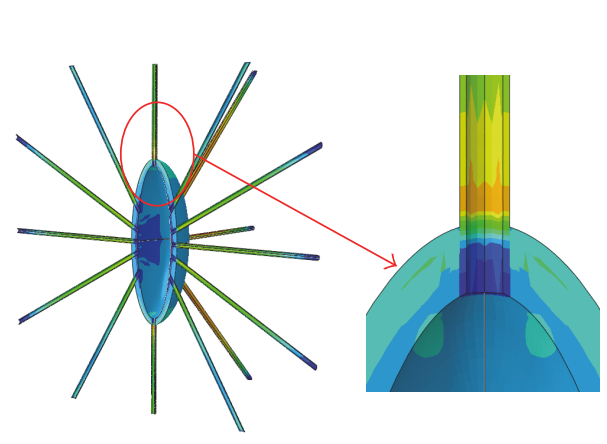

(b)
FLVEL, magnitude (Avg: $75 \%$ )

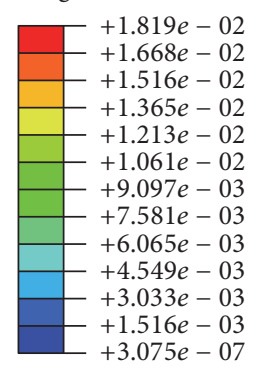

$+3.075 e-07$

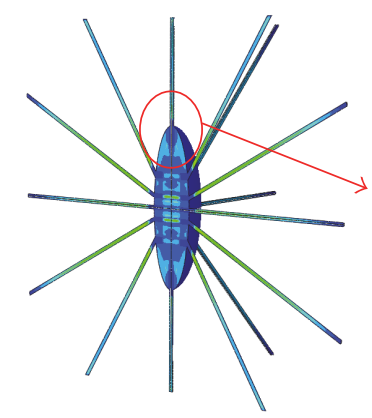

FLVEL, magnitude (Avg: $75 \%)$
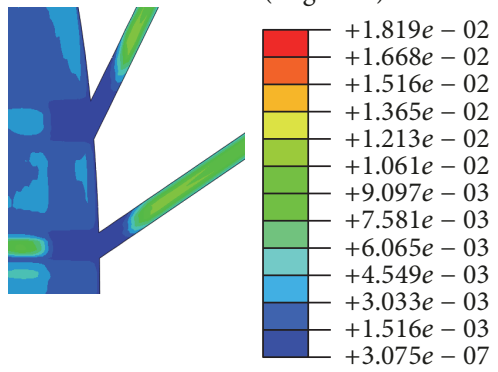

(c)

FIGURE 6: Fluid velocity distributions of the osteocyte-lacunar-canalicular system under the 1000-microstrain compressive loading. (a) Fluid velocities when $t=0.02,0.1,0.12,0.2$, and $1.0 T$, where $T$ is the relative period of loading; (b) fluid velocity distribution at canaliculi and perilacunar matrix when $t=0.1 T$; and (c) fluid velocity distribution at the osteocyte and processes.

The maximum fluid velocities of the FE model were found to be $2.69,18.19,56.65$, and $97.98 \mu \mathrm{m} / \mathrm{s}$ when the model was subjected to global compressive loads of 150, 1000, 3000, and 5000 microstrains, respectively. Figure 6 displays the fluid velocities of the FE model under the 1000-microstrain compression load. The fluid velocities changed only slightly after $t=0.2 T$. In a previous study, the peak fluid flow velocity in canaliculi of the bone lacunar-canalicular system was $60 \mu \mathrm{m} / \mathrm{s}$ under a surface strain of 400 -microstrain loading [70]. Recently, Wang et al. presented the range of fluid flow velocity of $13.1-69.3 \mu \mathrm{m} / \mathrm{s}$ under $298-$ and 510 -microstrain loading [71]. Compared to these experimental and theoretical velocity values, our predicted maximum fluid velocities of the FE model are within the reasonable and comparable ranges.

3.2. Distributions of the Maximum Principal Strains, Maximum Pore Pressures, and Maximum Fluid Velocities. In order to investigate the biomechanical responses of the cell body and processes, five points of the model in one straight line were selected for analyses (Figure 7(a)). Because the geometry of the osteocyte-lacunar-canalicular model is symmetrical, only one process and $1 / 8$ the cell body were analysed. Point $A$ is located at the end of the process which is near to the loading surface; point $B$ is near to the junction of the process and PCM; point $\mathrm{C}$ is at the top of the cell body and near the junction of the process and PCM; point $\mathrm{D}$ is about the middle of $1 / 8$ cell body; and point $\mathrm{E}$ is at the bottom of $1 / 8$ cell body (Figure 7(a)).

Detailed analyses of the maximum principal strains with loading time at these five different locations are shown in Figures $7(\mathrm{~b})-7(\mathrm{e})$ when the model was subjected to different compressive loads. As shown, the strain value of point $\mathrm{E}$ is bigger than those of the other points in the steady state; point $\mathrm{B}$ has the oscillation in the early phase and point $\mathrm{C}$ has the oscillation in most phases of loading time; and the values of points $\mathrm{A}$ and $\mathrm{D}$ are smaller than those of other points. In 

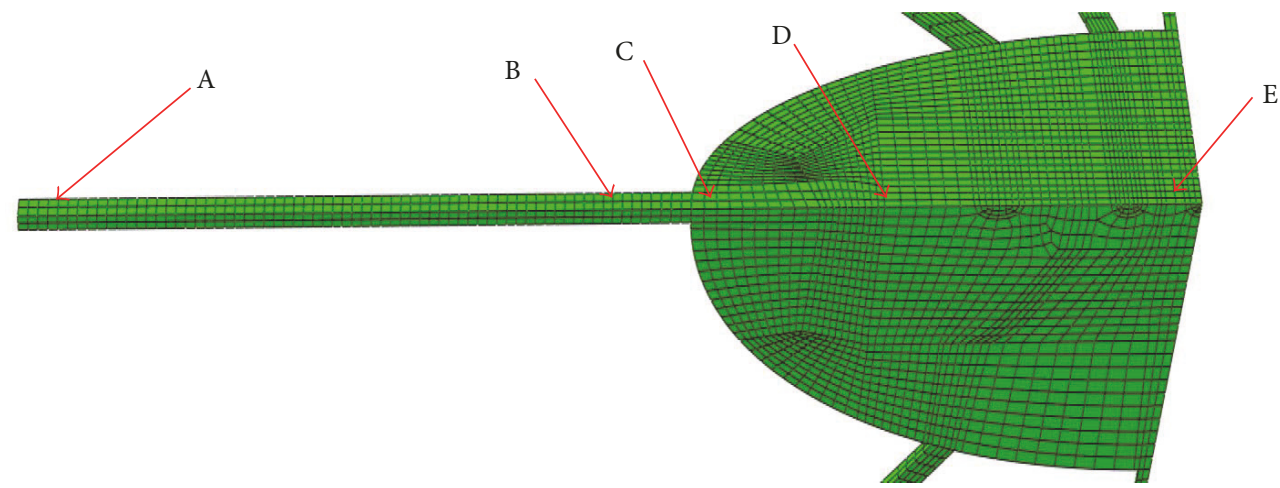

(a)
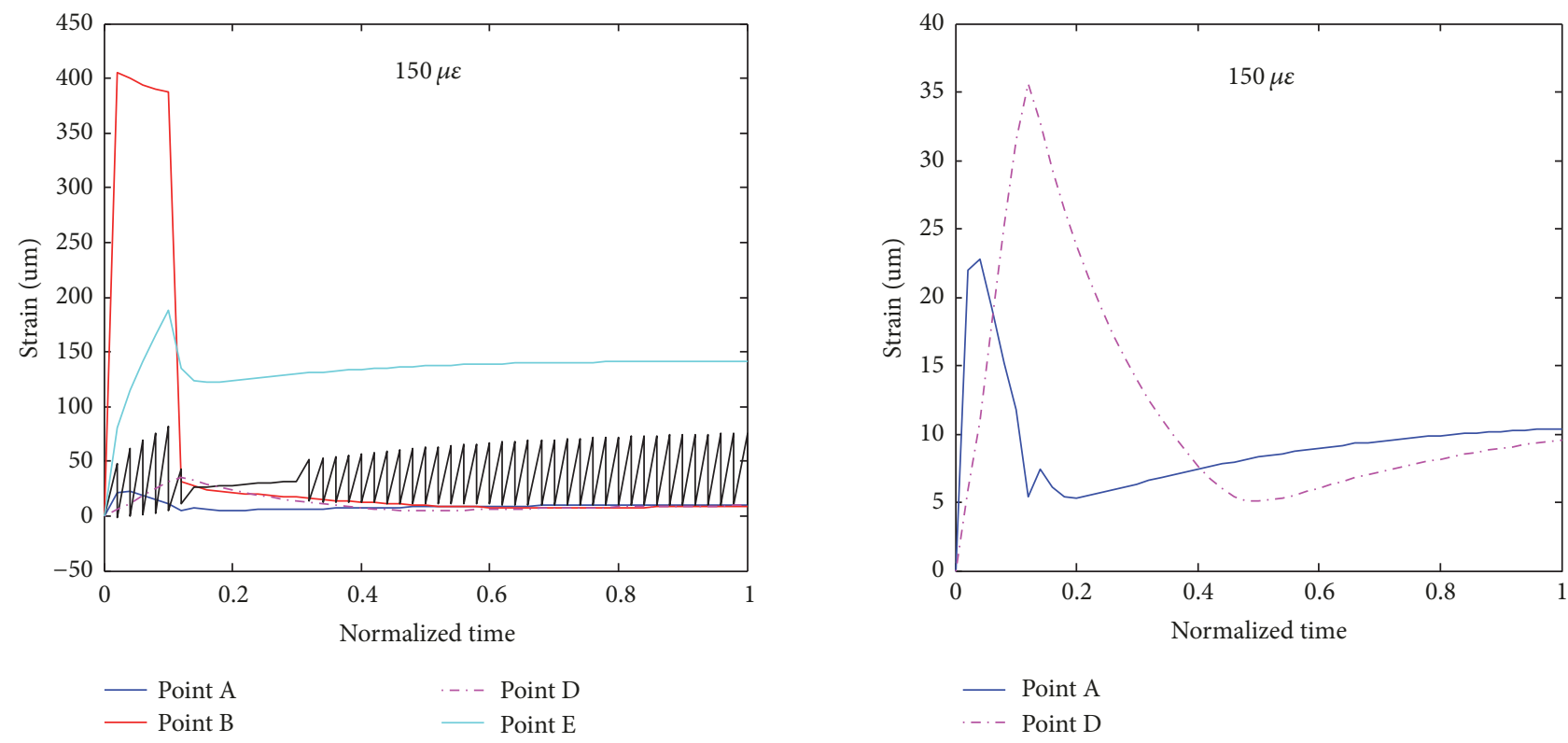

(b)
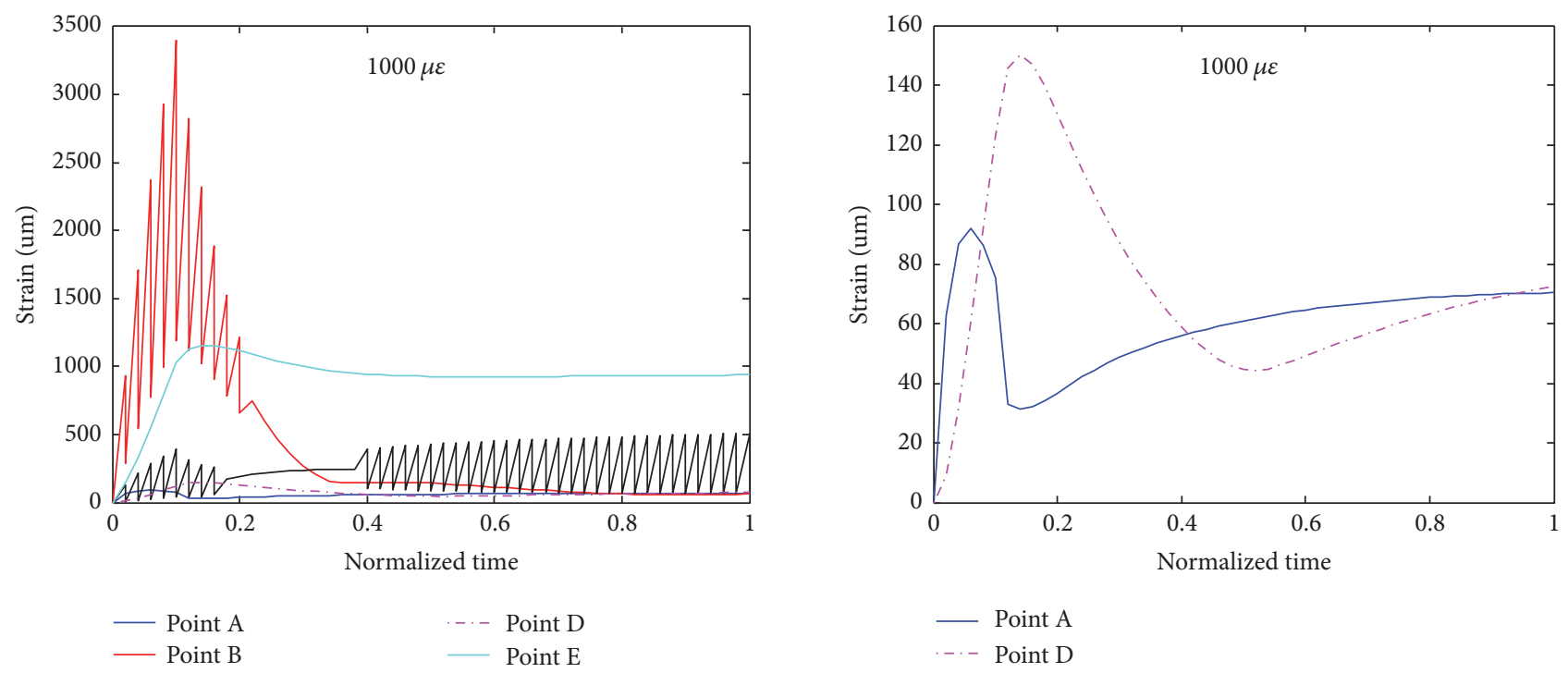

(c)

Figure 7: Continued. 

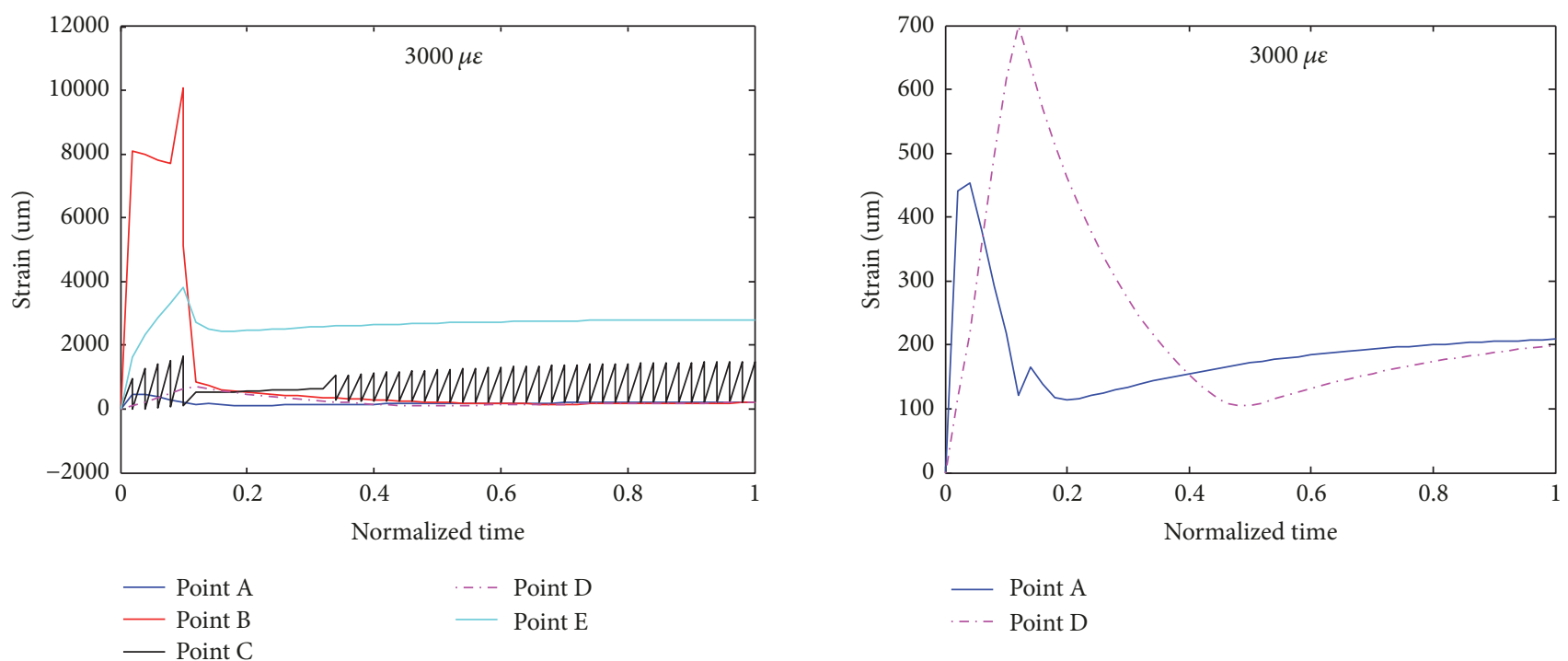

(d)
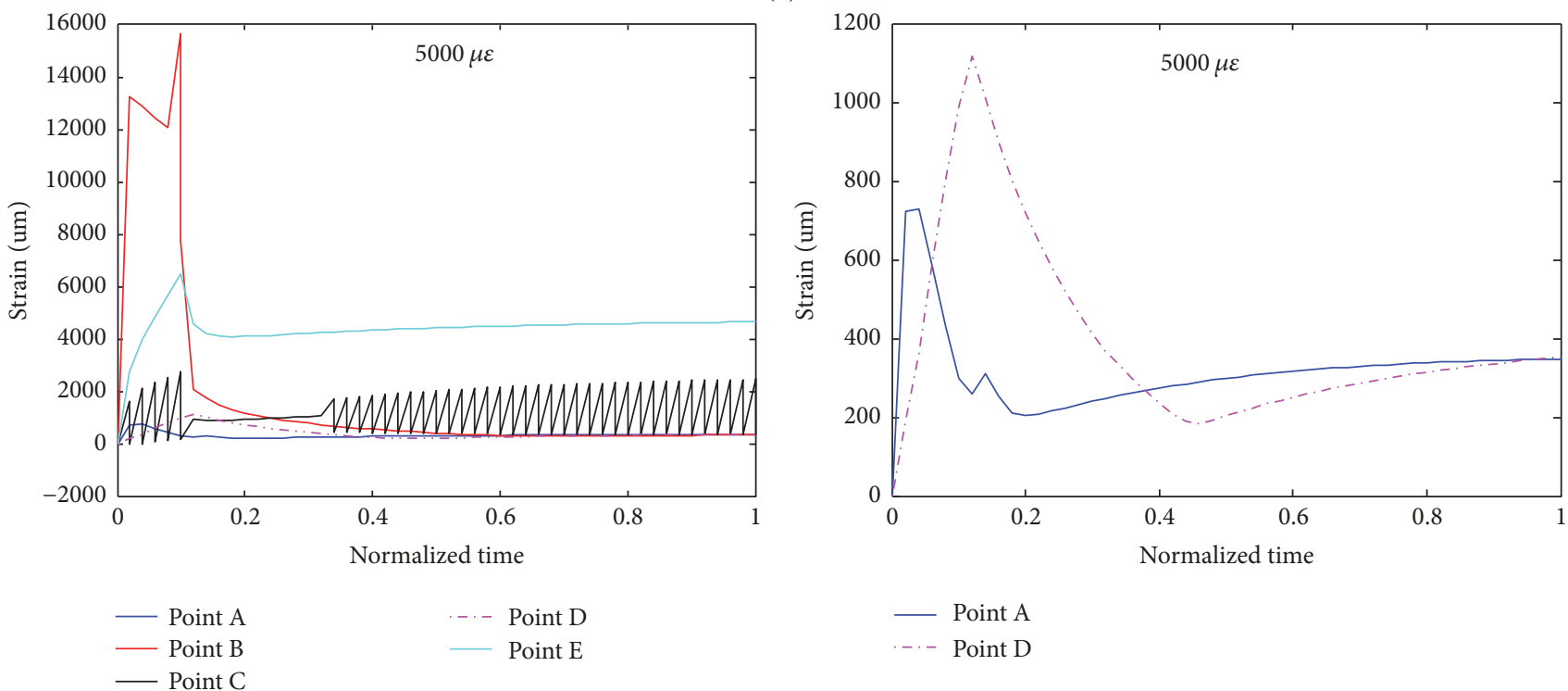

(e)

FIGURE 7: Detailed analyses of the maximum principal strains versus loading time at different locations (a) of the osteocyte cell body and a process when under different compressive loads ((b), (c), (d), and (e) for 150, 1000, 3000, and 5000 microstrains, respectively).

Figure 7, some oscillations occurred at point $\mathrm{C}$, which is at the top of the cell body and near the junction of the cell process and perilacunar matrix (PCM). Being at the junction of the cell body, process, and PCM, whose material properties were different, the responding displacement/strain of point $\mathrm{C}$ may thus oscillate under mechanical loads.

Figure 8 shows results of detailed analyses of the pore pressure distributions of the cell body and a process at the five different locations (points $\mathrm{A}, \mathrm{B}, \mathrm{C}, \mathrm{D}$, and $\mathrm{E}$ ) when the FE model was under the four different compressive loadings. As shown, the pore pressure of point B is larger than those of the other points and that at point $A$ it is smallest among these points.

Figure 9 presents results of detailed analyses of the fluid velocities of different locations (points $A, B, C, D$, and $E$ ) of cell body and a process when the model was under different compressive loadings. Fluid velocity of point B is larger than those of the other points in the steady state. In the early response phase, the fluid velocity of point A appears in oscillation and then reaches a value in the steady state. Point $\mathrm{A}$ is in distal end of the process. The fluid velocity of point $\mathrm{A}$ is more sensitive than other points during the ramp increase.

\section{Discussion}

It is now widely believed that fluid that flows through the osteocyte-lacunar-canalicular system can affect and control the bone adaptation since when the osteocytes are stimulated by fluid stress, they can produce biological signals that guide the recruitment/activity of osteoclasts and/or osteoblasts on 


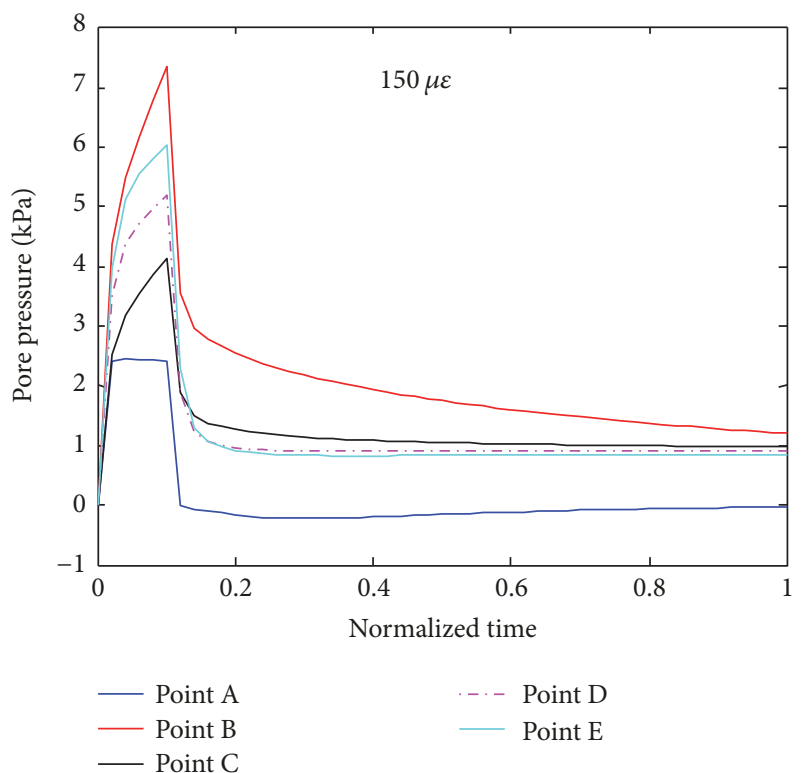

(a)

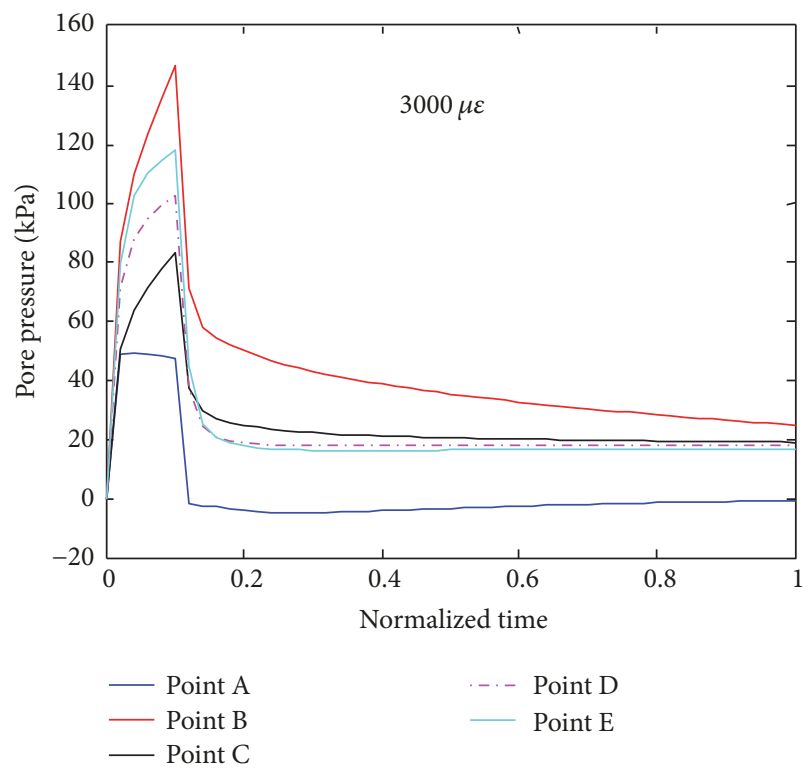

(c)

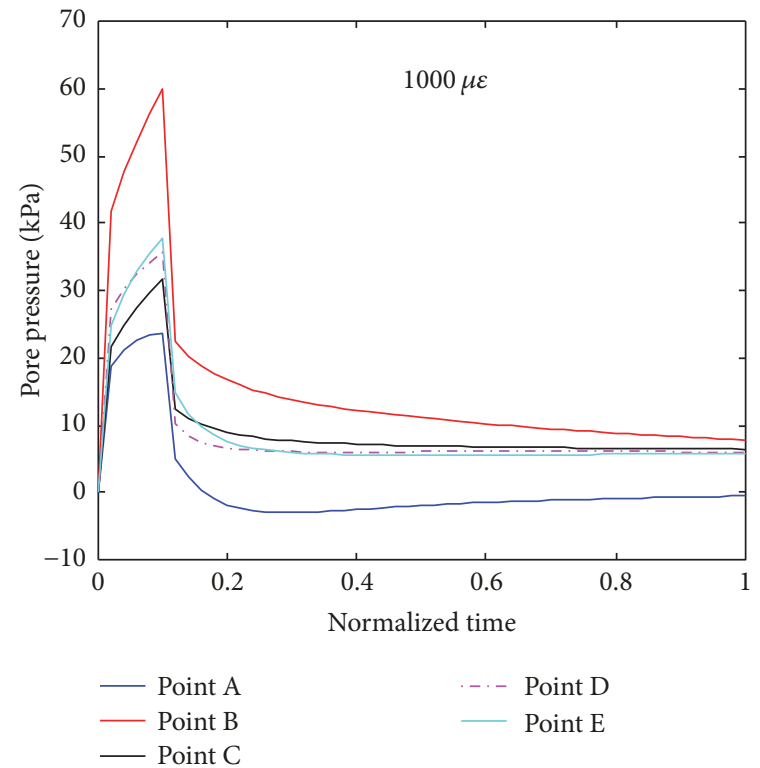

(b)

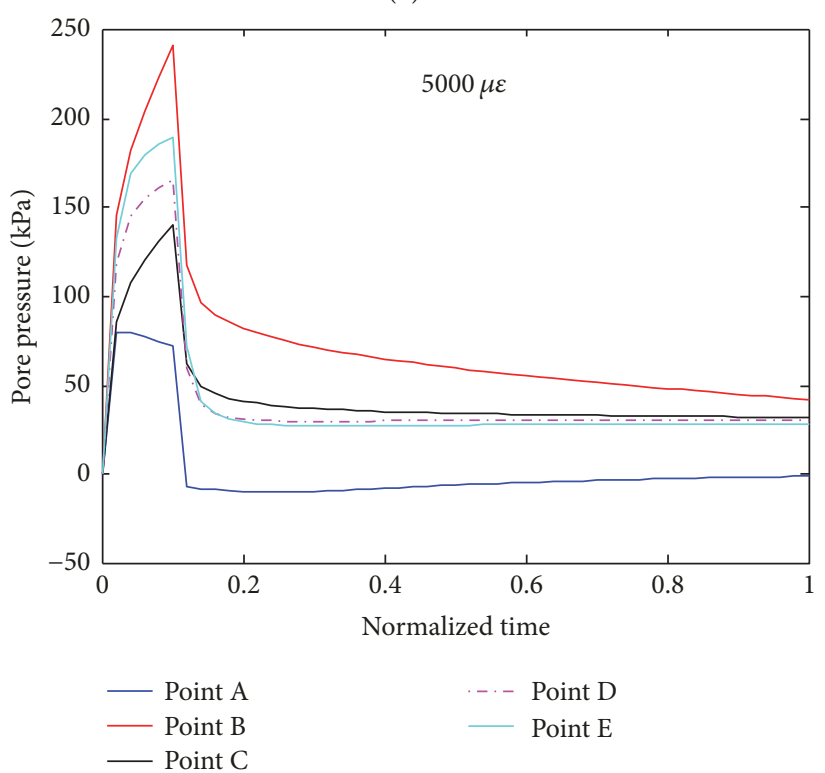

(d)

Figure 8: Detailed analyses of pore pressures versus loading time at different locations (defined in Figure 7(a)) of the osteocyte cell body and a process when the system was under different compressive loads ((a), (b), (c), and (d) for 150, 1000, 3000, and 5000 microstrains, respectively).

the surface of the bone [47]. Thus, the fluid embodied in osteocyte-lacunar-canalicular system is vital for the system to regulate bone remodelling [72]. Previously, various models including the FE analysis model have been used to study biomechanical behaviours of the osteocyte-lacunarcanalicular system. However, these previous studies have not taken the poroelastic properties into the FE model analysis. The current study has developed a FE model with one triaxial lacunar osteocyte ellipsoid and, by using a 3D poroelastic model under four different compressive loads, investigated the biomechanical responses (strain, pore pressure, and fluid velocity) of the osteocyte-lacunar-canalicular system. It is now known that different biomechanical responses can be produced by different mechanical stimulations [3], including the tensile loading when the bone is bended or pulled away from itself and the compressive loading caused by the force pushing the bone together (e.g., the animal's weight in the axial load component) [73]. Among these, the compressive load has been widely studied in osteocytes by using the FE analysis method [24, 26-28]. Although several analyses of the strain amplification in osteocytes using the poroelastic models have been reported $[18,74,75]$, these studies had focused on theoretical models, and the relative contribution of strain amplification has not been reported with 3D poroelastic FE models that are subjected to mechanical loading-like strains. In the current study, four 


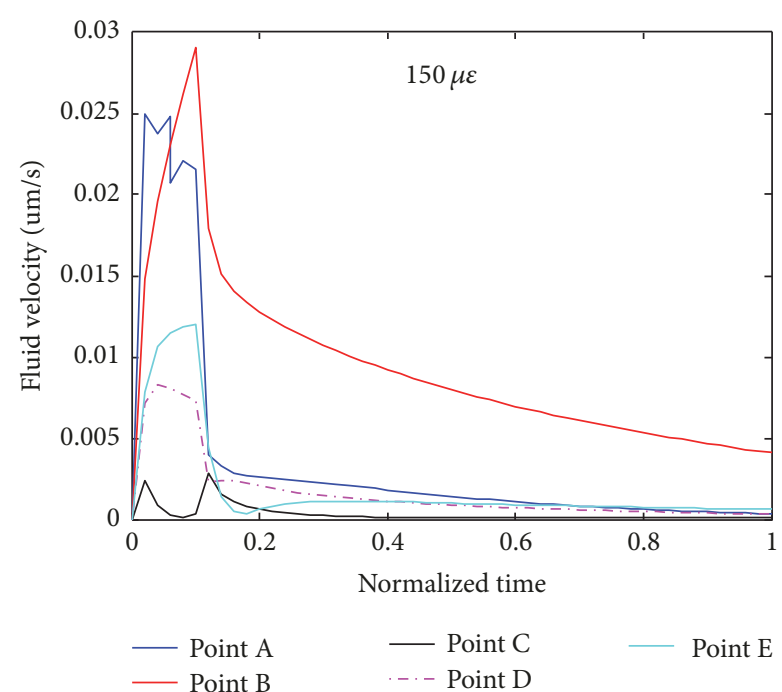

(a)

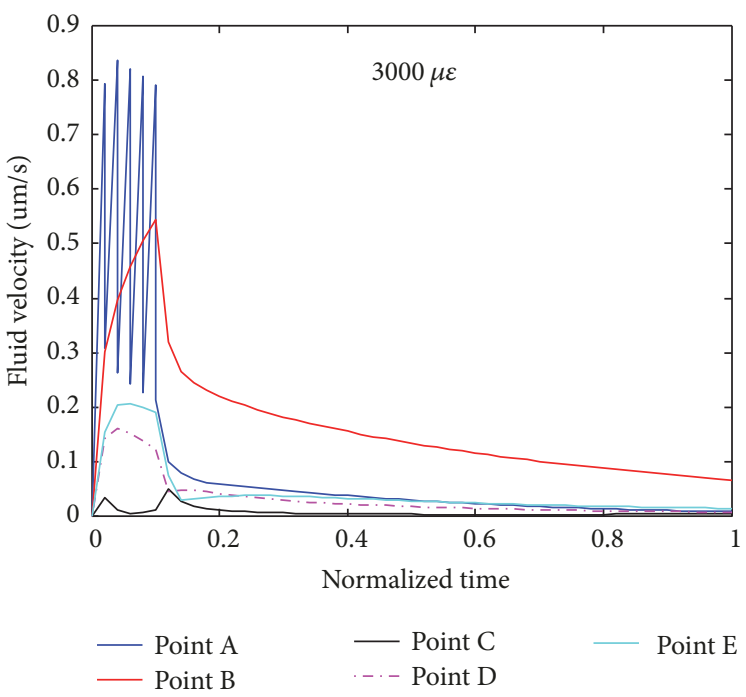

(c)

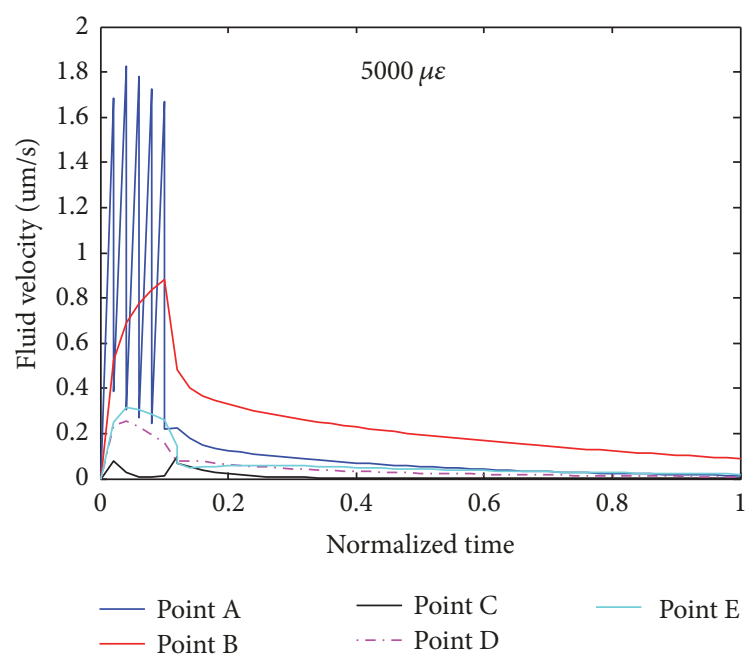

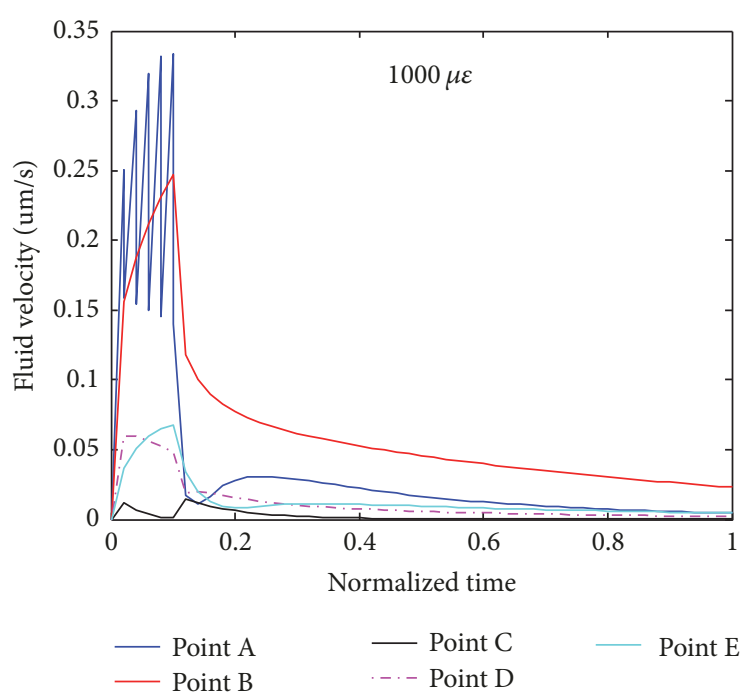

(b)
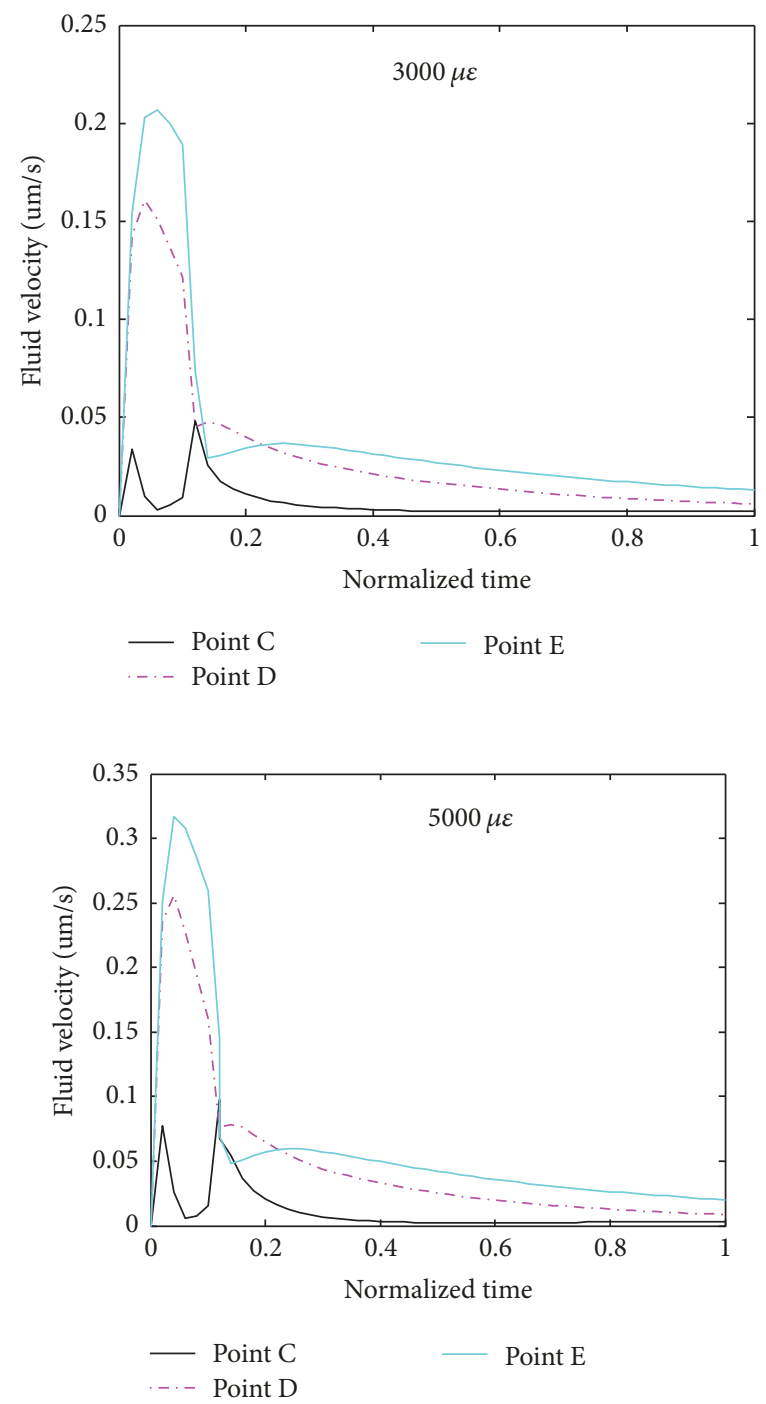

(d)

FIGURE 9: Detailed analyses of fluid velocities versus loading time at different locations (defined in Figure 7(a)) of the osteocyte cell body and a process when the system was under different compressive loads ((a), (b), (c), and (d) for 150, 1000, 3000, and 5000 microstrains, respectively). 
different degrees of compressive strain loads were applied to our 3D poroelastic FE model to investigate the biomechanical responses of the osteocyte-lacunar-canalicular system, that is, under 150 microstrains (disuse), 1000 microstrains (physiological), 3000 microstrains (overuse), and 5000 microstrains (pathological overload), respectively.

The simulation results of our poroelastic FE model under the compressive loads were found to be in good agreement with the previous results $[24,26,30,63,69,76]$. For example, our predicted maximum principal strain was 12820 microstrains under 3000-microstrain compressive load, and the corresponding result from Verbruggen et al. (2012) was 6600-12600 microstrains [26]. In addition, Bonivtch et al. (2007) predicted the local strain was 4000-6000 microstrains for the osteocyte lacuna under a 2000-microstrain compressive load [24]. Thus the predicted results from our poroelastic FE model are consistent with data from the literature. Since there is no validation data for the idealized model in the existing literature, our predicted result for the 5000-microstrain compressive load cannot be compared. A study indicated that the maximum principal strain was 5-fold higher than the global strain load [76]. In a recent biorealistic osteocyte model study, the local strain amplification factors were up to 10 and up to 70 in the ECM and in the osteocytes, respectively, and the peak amplitude of this model was 50,000-70,000 microstrains under the 1000microstrain global compression [30]. Data from the current study indicates that the strain amplification factors only changed very slightly with the different global loads applied, suggesting the strain amplification factor is not sensitive to the global loads.

Pore fluid pressure occurred when the osteocyte-lacunarcanalicular system is subjected to loads [42]. The osteocytelacunar-canalicular system is a high-fluid-pressure domain because the pore size of the system is very small, leading to a slow decay of a pressure pulse [31]. The current study has computed the pore fluid pressure distributions in the osteocyte cell body and processes under the compressive loadings applied. The maximum pore fluid pressures of cell body and processes were found to be $8.98,74.24,175.9$, and $285.7 \mathrm{kPa}$ when under 150, 1000, 3000, and 5000 microstrains, respectively. Previously, a modest pore fluid pressure in the lacuna was found to be $\sim 9.3 \mathrm{kPa}$ when under a 100 microstrain compressive load [19], and the maximal pore fluid pressure magnitude was $\sim 0.86,8.58$, and $85.35 \mathrm{kPa}$ when the permeability was $10^{-18}, 10^{-19}$, and $10^{-20} \mathrm{~m}^{2}$, respectively [42]. In addition, maximum pore pressure was up to $250 \mathrm{kPa}$ when the cortical bone was subjected to $1 \mathrm{Mpa}$ uniaxial stress [50], and the maximum hydraulic pressure of lacunarcanalicular system was up to $5 \mathrm{MPa}$ when an osteon was under 1000-microstrain compression at $1 \mathrm{~Hz}$ frequency [15]. Our predicted results of pore fluid pressure are thus consistent with the findings of these previous studies. In addition, these data suggest that the pore pressure increases with the increasing global loading.

Furthermore, using the present model, fluid velocity was also predicted and simulation was conducted for fluid flow within the osteocyte-lacunar-canalicular system in situ. In our model, the maximum fluid velocities were $2.69,18.19$, 56.65, and $97.98 \mu \mathrm{m} / \mathrm{s}$ under 150, 1000, 3000, and 5000 microstrains, respectively, suggesting that the fluid velocity increases with the increasing global loading. Fluid velocity is another important characteristic of the response of an osteocyte to the mechanical loading stimuli, since fluid movement within the lacunar-canalicular system caused by mechanical loading can cause small deformations of bone, deliver nutrients to, and remove wastes from the osteocytes [77], and the small fluid shear stress acting on PCM and the osteocyte processes can regulate the lacunar-canalicular system [14].

Moreover, the distributions of the strain, pore pressure, and fluid velocity of five selected points in the cell and a process were investigated over the whole loading time period and under different degrees of compressive loading. It was found that the values of these parameters increased firstly and reached the peak values at about the $0.1 T$, followed by declining and finally reaching the steady states. Overall, these trends of changes are coincident with the mode of loading with the load increasing starting from the initial point and reaching the highest load at $0.1 T$. Furthermore, among the selected locations analysed, the proximal side (near to the cell) of a process was found to bear the highest local strain, pore pressure, and fluid velocity. In addition, among the various degrees of loads applied, it was found that the degrees of biomechanical responses increase with mechanical loads. In other words, the local strain, pore pressure, and fluid velocity of the cell and a process increase with the global loading. Because the loading time and the ramp time were kept the same, the high compressive loading occurred with sharper loading ramps and caused much higher velocity, pressure, and principal strains peaks.

In the current study, the poroelastic material property was applied in all simulations. The osteocyte-lacunar-canalicular system is considered to be fully saturated, having only a solid matrix phase and a fluid phase with no air voids, and it consists of the fluid spaces surrounding the osteocytes and their processes. In most previous studies, the porosity of osteocyte-lacunar-canalicular system was assumed to be 0.05 $[39,47,72,78]$. However, in some studies, the values were variable, being as low as 0.023 in man [79], 0.042 in dogs [80], and even 0.007 in mice [81], and as high as 0.14 in rats [82].

Moreover, the permeability (the ease with which the fluid can move within a porous system) which is related to porosity, is also a very important measure for the poroelastic model. In the current study, viscosity was assumed $0.001 \mathrm{~Pa}$ s (i.e., viscosity of water). Permeability depends on the number, orientation, and size of the canaliculi, as well as on the amount of filling by osteocytes and their processes. While it is too hard to determine it directly, there have been estimations of permeability of the osteocyte-lacunar-canalicular systems ranging over 8 orders of magnitude [52], with the estimated values ranging from $5 \times 10^{-25}$ to $7.172 \times 10^{-17}\left(\mathrm{~m}^{2}\right)$ $[19,42,55,72,78,83,84]$. The value of permeability was determined or estimated by different methods, for example, the theoretical method $[19,52,83]$, experimental method $[47,78]$, and nanoindentation technology [85]. Such variation 
in the reported/estimated values may be a consequence of many factors, including differences in theoretical assumptions/boundary conditions, experimental errors associated with the nested porosities in bone which are difficult to isolate, the freshness of the tissue tested, and the presence of the soft tissues inside the lacunae and canaliculi [31]. According to the analysis from a previous study [31], to be able to produce fluid flow inside canaliculi and stimulate osteocytes, the permeability in the lacunar-canalicular domain should be $\sim 10^{-20} \mathrm{~m}^{2}$ or smaller. In our study, the permeability values are $0.6 \times 10^{-19}, 4 \times 10^{-20}$, and $5.0 \times$ $10^{-15} \mathrm{~m}^{2}$ in the cell body and process, in PCM and canaliculi, and in the ECM, respectively. The permeability is not a constant value and thus the strain-dependent permeability was implemented in the present FE model. Our result is consistent with Darcy's law that the fluid velocity and pore pressure vary with the hydraulic permeability. Our study indicates that the poroelastic material property can affect the biomechanical responses to the mechanical stimulus and the permeability is important in controlling the fluid flow behaviours in the poroelastic model.

\section{Conclusions}

Although there have been some previous studies using FE analysis models mostly under compressive loads to examine biomechanical behaviours of the osteocyte-lacunarcanalicular system, these studies had not taken the bone poroelastic properties into account. The current study has developed a 3D poroelastic idealized FE model to investigate the biomechanical responses of the osteocyte-lacunarcanalicular system under different degrees of compressive loading stimuli. It was found that predicted maximum principal strains of osteocytes were $\sim 633,4272,12820$, and 21528; the maximum pore pressures were $\sim 8.98,74.24,175.9$, and $285.7 \mathrm{kPa}$; and the maximum fluid velocity values were $2.69,18.19,56.65$, and $97.98 \mu \mathrm{m} / \mathrm{s}$ when the model was under 150 microstrains (disuse), 1000 microstrains (physiological), 3000 microstrains (overuse), and 5000 microstrains (pathological overload), respectively. The values of the strain, pore pressure, and fluid velocity, which were found to be the highest at the proximal region of cell processes, increase with the global loading. This new model can potentially be used to predict the mechanobiological behaviours of osteocytes under physiological or pathological loadings, which may provide an insight into understanding the mechanisms of mechanosensation and mechanotransduction of the bone.

\section{Conflicts of Interest}

The authors declare that they have no conflicts of interest.

\section{Authors' Contributions}

Liping Wang and Cory J. Xian conceived and designed the simulations and wrote the paper. Liping Wang and Jianghui Dong performed the simulations. Liping Wang analysed the data. Liping Wang, Jianghui Dong, and Cory J. Xian contributed reagents/materials/analysis tools.

\section{Acknowledgments}

This work was supported by Natural Science Foundation of China project grant (81671928). Liping Wang is supported by Australian National Health and Medical Research Council (NHMRC) Postgraduate Research Scholarship grant, and Cory J. Xian is supported by the NHMRC Senior Research Fellowship.

\section{References}

[1] L. You, S. Weinbaum, S. C. Cowin, and M. B. Schaffler, "Ultrastructure of the osteocyte process and its pericellular matrix," The Anatomical Record, vol. 278A, no. 2, pp. 505-513, 2004.

[2] A. R. Stern and D. P. Nicolella, "Measurement and estimation of osteocyte mechanical strain," Bone, vol. 54, no. 2, pp. 191-195, 2013.

[3] E. B. Rego, T. Inubushi, A. Kawazoe et al., "Effect of $\mathrm{PGE}_{2}$ induced by compressive and tensile stresses on cementoblast differentiation in vitro," Archives of Oral Biolog, vol. 56, no. 11, pp. 1238-1246, 2011.

[4] A. L. Rath, L. F. Bonewald, J. Ling, J. X. Jiang, M. E. Van Dyke, and D. P. Nicolella, "Correlation of cell strain in single osteocytes with intracellular calcium, but not intracellular nitric oxide, in response to fluid flow," Journal of Biomechanics, vol. 43, no. 8, pp. 1560-1564, 2010.

[5] L. F. Bonewald, "Osteocytes as dynamic multifunctional cells," Annals of the New York Academy of Sciences, vol. 1116, pp. 281290, 2007.

[6] M. Capulli, R. Paone, and N. Rucci, "Osteoblast and osteocyte: games without frontiers," Archives of Biochemistry and Biophysics, vol. 561, pp. 3-12, 2014.

[7] A. J. Michalek and J. C. Iatridis, "A numerical study to determine pericellular matrix modulus and evaluate its effects on the micromechanical environment of chondrocytes," Journal of Biomechanics, vol. 40, no. 6, pp. 1405-1409, 2007.

[8] L. F. Bonewald, “The amazing osteocyte," Journal of Bone and Mineral Research, vol. 26, no. 2, pp. 229-238, 2011.

[9] C. Fotia, G. M. L. Messina, G. Marletta, N. Baldini, and G. Ciapetti, "Hyaluronan-based pericellular matrix: substrate electrostatic charges and early cell adhesion events," European Cells and Materials, vol. 26, pp. 133-149, 2013.

[10] J. Klein-Nulend, A. D. Bakker, R. G. Bacabac, A. Vatsa, and S. Weinbaum, "Mechanosensation and transduction in osteocytes," Bone, vol. 54, no. 2, pp. 182-190, 2013.

[11] E. H. Burger and J. Klein-Nulend, "Mechanotransduction in bone-role of the lacuno-canalicular network," The FASEB Journal, vol. 13, no. 8, pp. S101-S112, 1999.

[12] M. D. Johnston, C. M. Edwards, W. F. Bodmer, P. K. Maini, and S. J. Chapman, "Examples of mathematical modeling: Tales from the crypt," Cell Cycle, vol. 6, no. 17, pp. 2106-2112, 2007.

[13] R. H. Kufahl and S. Saha, "A theoretical model for stressgenerated fluid flow in the canaliculi-lacunae network in bone tissue," Journal of Biomechanics, vol. 23, no. 2, pp. 171-180, 1990.

[14] S. Weinbaum, S. C. Cowin, and Y. Zeng, "A model for the excitation of osteocytes by mechanical loading-induced bone fluid shear stresses," Journal of Biomechanics, vol. 27, no. 3, pp. 339-360, 1994.

[15] Y. Zeng, S. C. Cowin, and S. Weinbaum, "A fiber matrix model for fluid flow and streaming potentials in the canaliculi of an 
osteon," Annals of Biomedical Engineering, vol. 22, no. 3, pp. 280-292, 1994.

[16] Y. Wang, L. M. McNamara, M. B. Schaffler, and S. Weinbaum, "A model for the role of integrins in flow induced mechanotransduction in osteocytes," Proceedings of the National Acadamy of Sciences of the United States of America, vol. 104, no. 40, pp. 15941-15946, 2007.

[17] L. Wang, S. C. Cowin, S. Weinbaum, and S. P. Fritton, "Modeling tracer transport in an osteon under cyclic loading," Annals of Biomedical Engineering, vol. 28, no. 10, pp. 1200-1209, 2000.

[18] Y. Han, S. C. Cowin, M. B. Schaffler, and S. Weinbaum, "Mechanotransduction and strain amplification in osteocyte cell processes," Proceedings of the National Acadamy of Sciences of the United States of America, vol. 101, no. 47, pp. 16689-16694, 2004.

[19] S. Gururaja, H. J. Kim, C. C. Swan, R. A. Brand, and R. S. Lakes, "Modeling deformation-induced fluid flow in cortical bone's canalicular-lacunar system," Annals of Biomedical Engineering, vol. 33, no. 1, pp. 7-25, 2005.

[20] S. V. N. Jaecques, H. Van Oosterwyck, L. Muraru et al., "Individualised, micro CT-based finite element modelling as a tool for biomechanical analysis related to tissue engineering of bone," Biomaterials, vol. 25, no. 9, pp. 1683-1696, 2004.

[21] R. Hambli, "Connecting mechanics and bone cell activities in the bone remodeling process: an integrated finite element modeling," Frontiers in Bioengineering and Biotechnology, vol. 2, 2014.

[22] L. Podshivalov, A. Fischer, and P. Z. Bar-Yoseph, "On the road to personalized medicine: multiscale computational modeling of bone tissue," Archives of Computational Methods in Engineering: State-of-the-Art Reviews, vol. 21, no. 4, pp. 399-479, 2014.

[23] B. R. McCreadie and S. J. Hollister, "Strain concentrations surrounding an ellipsoid model of lacunae and osteocytes," Computer Methods in Biomechanics and Biomedical Engineering, vol. 1, no. 1, pp. 61-68, 1997.

[24] A. R. Bonivtch, L. F. Bonewald, and D. P . Nicolella, “Tissue strain amplification at the osteocyte lacuna: a microstructural finite element analysis," Journal of Biomechanics, vol. 40, no. 10, pp. 2199-2206, 2007.

[25] J. A. Sanz-Herrera, J. M. García-Aznar, and M. Doblaré, “Micromacro numerical modelling of bone regeneration in tissue engineering," Computer Methods Applied Mechanics and Engineering, vol. 197, no. 33-40, pp. 3092-3107, 2008.

[26] S. W. Verbruggen, T. J. Vaughan, and L. M. McNamara, "Strain amplification in bone mechanobiology: a computational investigation of the in vivo mechanics of osteocytes," Journal of the Royal Society Interface, vol. 9, no. 75, pp. 2735-2744, 2012.

[27] B. Hesse, P. Varga, M. Langer et al., "Canalicular network morphology is the major determinant of the spatial distribution of mass density in human bone tissue: Evidence by means of synchrotron radiation phase-contrast nano-CT," Journal of Bone and Mineral Research, vol. 30, no. 2, pp. 346-356, 2015.

[28] L. Wang, J. Dong, and C. J. Xian, "Strain amplification analysis of an osteocyte under static and cyclic loading: a finite element study," BioMed Research International, vol. 2015, Article ID 376474, 14 pages, 2015.

[29] J. Qiu, A. D. Baik, X. L. Lu et al., "A noninvasive approach to determine viscoelastic properties of an individual adherent cell under fluid flow," Journal of Biomechanics, vol. 47, no. 6, pp. 1537-1541, 2014.

[30] P. Varga, B. Hesse, M. Langer et al., "Synchrotron X-ray phase nano-tomography-based analysis of the lacunar-canalicular network morphology and its relation to the strains experienced by osteocytes in situ as predicted by case-specific finite element analysis," Biomechanics and Modeling in Mechanobiology, vol. 14, no. 2, pp. 267-282, 2015.

[31] L. Cardoso, S. P. Fritton, G. Gailani, M. Benalla, and S. C. Cowin, "Advances in assessment of bone porosity, permeability and interstitial fluid flow," Journal of Biomechanics, vol. 46, no. 2, pp. 253-265, 2013.

[32] G. C. Goulet, N. Hamilton, D. Cooper et al., "Influence of vascular porosity on fluid flow and nutrient transport in loaded cortical bone," Journal of Biomechanics, vol. 41, no. 10, pp. 21692175, 2008.

[33] S. P. Fritton and S. Weinbaum, "Fluid and solute transport in bone: flow-induced mechanotransduction," Annual Review of Fluid Mechanics, vol. 41, pp. 347-374, 2009.

[34] M. Lovett, K. Lee, A. Edwards, and D. L. Kaplan, "Vascularization strategies for tissue engineering," Tissue Engineering Part B: Reviews, vol. 15, no. 3, pp. 353-370, 2009.

[35] K. M. Reich, C. V. Gay, and J. A. Frangos, "Fluid shear stress as a mediator of osteoblast cyclic adenosine monophosphate production," Journal of Cellular Physiology, vol. 143, no. 1, pp. 100-104, 1990.

[36] K. M. Reich and J. A. Frangos, "Effect of flow on prostaglandin E2 and inositol trisphosphate levels in osteoblasts," American Journal of Physiology-Cell Physiology, vol. 261, no. 3, pp. C428C432, 1991.

[37] M. L. Knothe Tate, P. Niederer, and U. Knothe, "In vivo tracer transport through the lacunocanalicular system of rat bone in an environment devoid of mechanical loading," Bone, vol. 22, no. 2, pp. 107-117, 1998.

[38] A. F. T. Mak, D. T. Huang, J. D. Zhang, and P. Tong, "Deformation-induced hierarchical flows and drag forces in bone canaliculi and matrix microporosity," Journal of Biomechanics, vol. 30, no. 1, pp. 11-18, 1997.

[39] S. C. Cowin, "Bone poroelasticity," Journal of Biomechanics, vol. 32, no. 3, pp. 217-238, 1999.

[40] G. B. Gailani and S. C. Cowin, "The unconfined compression of a poroelastic annular cylindrical disk," Mechanics of Materials, vol. 40, no. 6, pp. 507-523, 2008.

[41] S. C. Cowin and M. M. Mehrabadi, "Compressible and incompressible constituents in anisotropic poroelasticity: the problem of unconfined compression of a disk," Journal of the Mechanics and Physics of Solids, vol. 55, no. 1, pp. 161-193, 2007.

[42] G. C. Goulet, D. Coombe, R. J. Martinuzzi, and R. F. Zernicke, "Poroelastic evaluation of fluid movement through the lacunocanalicular system," Annals of Biomedical Engineering, vol. 37, no. 7, pp. 1390-1402, 2009.

[43] G. Gailani and S. Cowin, "Ramp loading in Russian doll poroelasticity," Journal of the Mechanics and Physics of Solids, vol. 59, no. 1, pp. 103-120, 2011.

[44] P. E. Palacio-Mancheno, A. I. Larriera, S. B. Doty, L. Cardoso, and S. P. Fritton, "3D assessment of cortical bone porosity and tissue mineral density using high-resolution $\mu \mathrm{cT}$ : Effects of resolution and threshold method," Journal of Bone and Mineral Research, vol. 29, no. 1, pp. 142-150, 2014.

[45] T. D. Nguyen, A. Oloyede, and Y. Gu, "A poroviscohyperelastic model for numerical analysis of mechanical behavior of single chondrocyte," Computer Methods in Biomechanics and Biomedical Engineering, vol. 19, no. 2, pp. 126-136, 2016.

[46] T.-H. Lim and J. H. Hong, "Poroelastic properties of bovine vertebral trabecular bone," Journal of Orthopaedic Research, vol. 18, no. 4, pp. 671-677, 2000. 
[47] T. H. Smit, J. M. Huyghe, and S. C. Cowin, "Estimation of the poroelastic parameters of cortical bone," Journal of Biomechanics, vol. 35, no. 6, pp. 829-835, 2002.

[48] U. Andreaus, I. Giorgio, and A. Madeo, "Modeling of the interaction between bone tissue and resorbable biomaterial as linear elastic materials with voids," Zeitschrift für Angewandte Mathematik und Physik, vol. 66, no. 1, pp. 209-237, 2014.

[49] I. Giorgio, U. Andreaus, D. Scerrato, and F. dell'Isola, "A visco-poroelastic model of functional adaptation in bones reconstructed with bio-resorbable materials," Biomechanics and Modeling in Mechanobiology, vol. 15, no. 5, pp. 1325-1343, 2016.

[50] C. C. Swan, R. S. Lakes, R. A. Brand, and K. J. Stewart, "Micromechanically based poroelastic modeling of fluid flow in Haversian bone," Journal of Biomechanical Engineering, vol. 125, no. 1, pp. 25-37, 2003.

[51] B. R. McCreadie, S. J. Hollister, M. B. Schaffler, and S. A. Goldstein, "Osteocyte lacuna size and shape in women with and without osteoporotic fracture," Journal of Biomechanics, vol. 37, no. 4, pp. 563-572, 2004.

[52] L. Wang, S. P. Fritton, S. C. Cowin, and S. Weinbaum, "Fluid pressure relaxation depends upon osteonal microstructure: Modeling an oscillatory bending experiment," Journal of Biomechanics, vol. 32, no. 7, pp. 663-672, 1999.

[53] R. L. Duncan and C. H. Turner, "Mechanotransduction and the functional response of bone to mechanical strain," Calcified Tissue International, vol. 57, no. 5, pp. 344-358, 1995.

[54] N. Basso and J. N. M. Heersche, "Characteristics of in vitro osteoblastic cell loading models," Bone, vol. 30, no. 2, pp. 347351, 2002.

[55] T. Beno, Y.-J. Yoon, S. C. Cowin, and S. P. Fritton, "Estimation of bone permeability using accurate microstructural measurements," Journal of Biomechanics, vol. 39, no. 13, pp. 2378-2387, 2006.

[56] L. M. McNamara, R. J. Majeska, S. Weinbaum, V. Friedrich, and M. B. Schaffler, "Attachment of osteocyte cell processes to the bone matrix," Anatomical Record, vol. 292, no. 3, pp. 355-363, 2009.

[57] U. E. Pazzaglia and T. Congiu, "The cast imaging of the osteon lacunar-canalicular system and the implications with functional models of intracanalicular flow," Journal of Anatomy, vol. 222, no. 2, pp. 193-202, 2013.

[58] M. L. Knothe Tate, R. Steck, and E. J. Anderson, "Bone as an inspiration for a novel class of mechanoactive materials," Biomaterials, vol. 30, no. 2, pp. 133-140, 2009.

[59] E. K. Moo, W. Herzog, S. K. Han, N. A. Abu Osman, B. Pingguan-Murphy, and S. Federico, "Mechanical behaviour of in-situ chondrocytes subjected to different loading rates: A finite element study," Biomechanics and Modeling in Mechanobiology, vol. 11, no. 7, pp. 983-993, 2012.

[60] E. K. Moo, S. K. Han, S. Federico et al., "Extracellular matrix integrity affects the mechanical behaviour of in-situ chondrocytes under compression," Journal of Biomechanics, vol. 47, no. 5, pp. 1004-1013, 2014.

[61] T. D. Nguyen and Y. Gu, "Determination of strain-ratedependent mechanical behavior of living and fixed osteocytes and chondrocytes using atomic force microscopy and inverse finite element analysis," Journal of Biomechanical Engineering, vol. 136, no. 10, Article ID 101004, 2014.

[62] D. B. Burr, C. Milgrom, and D. Fyhrie, "In vivo measurement of human tibial strains during vigorous activity," Bone, vol. 18, no. 5, pp. 405-410, 1996.
[63] D. P. Nicolella, D. E. Moravits, A. M. Gale, L. F. Bonewald, and J. Lankford, "Osteocyte lacunae tissue strain in cortical bone," Journal of Biomechanics, vol. 39, no. 9, pp. 1735-1743, 2006.

[64] W. M. Lai, V. C. Mow, and V. Roth, "Effects of nonlinear strain-dependent permeability and rate of compression on the stress behavior of articular cartilage," Journal of Biomechanical Engineering, vol. 103, no. 2, pp. 61-66, 1981.

[65] M. K. Kwan, W. M. Lai, and V. C. Mow, "A finite deformation theory for cartilage and other soft hydrated connective tissuesI. Equilibrium results," Journal of Biomechanics, vol. 23, no. 2, pp. 145-155, 1990.

[66] M. H. Holmes, "Finite deformation of soft tissue: Analysis of a mixture model in uni-axial compression," Journal of Biomechanical Engineering, vol. 108, no. 4, pp. 372-381, 1986.

[67] M. Argoubi and A. Shirazi-Adl, "Poroelastic creep response analysis of a lumbar motion segment in compression," Journal of Biomechanics, vol. 29, no. 10, pp. 1331-1339, 1996.

[68] M. H. Holmes and V. C. Mow, "The nonlinear characteristics of soft gels and hydrated connective tissues in ultrafiltration," Journal of Biomechanics, vol. 23, no. 11, pp. 1145-1156, 1990.

[69] D. P. Nicolella and J. Lankford, "Microstructural strain near osteocyte lacuna in cortical bone in vitro," Journal of Musculoskeletal and Neuronal Interactions, vol. 2, no. 3, pp. 261-263, 2002.

[70] C. Price, X. Zhou, W. Li, and L. Wang, "Real-time measurement of solute transport within the lacunar-canalicular system of mechanically loaded bone: Direct evidence for load-induced fluid flow," Journal of Bone and Mineral Research, vol. 26, no. 2, pp. 277-285, 2011.

[71] B. Wang, X. Zhou, C. Price, W. Li, J. Pan, and L. Wang, "Quantifying load-induced solute transport and solute-matrix interaction within the osteocyte lacunar-canalicular system," Journal of Bone and Mineral Research, vol. 28, no. 5, pp. 10751086, 2013.

[72] S. C. Cowin, G. Gailani, and M. Benalla, "Hierarchical poroelasticity: movement of interstitial fluid between porosity levels in bones," Philosophical Transactions of the Royal Society A: Mathematical, Physical \& Engineering Sciences, vol. 367, no. 1902, pp. 3401-3444, 2009.

[73] M. J. Gomez-Benito, L. A. Gonzalez-Torres, E. Reina-Romo, J. Grasa, B. Seral, and et al., "Influence of high-frequency cyclical stimulation on the bone fracture-healing process: mathematical and experimental models," Philosophical Transactions of the Royal Society A: Mathematical, Physical \& Engineering Sciences, vol. 369, no. 1954, pp. 4278-4294, 2011.

[74] L. You, S. C. Cowin, M. B. Schaffler, and S. Weinbaum, "A model for strain amplification in the actin cytoskeleton of osteocytes due to fluid drag on pericellular matrix," Journal of Biomechanics, vol. 34, no. 11, pp. 1375-1386, 2001.

[75] Y. Wang, L. M. McNamara, M. B. Schaffler, and S. Weinbaum, "Strain amplification and integrin based signaling in osteocytes," Journal of Musculoskeletal and Neuronal Interactions, vol. 8, no. 4, pp. 332-334, 2008.

[76] S. Wentzell, R. Sterling Nesbitt, J. Macione, and S. Kotha, "Measuring strain using digital image correlation of second harmonic generation images," Journal of Biomechanics, vol. 46, no. 12, pp. 2032-2038, 2013.

[77] K. Piekarski and M. Munro, "Transport mechanism operating between blood supply and osteocytes in long bones," Nature, vol. 269, no. 5623, pp. 80-82, 1977.

[78] G. Gailani, M. Benalla, R. Mahamud, S. C. Cowin, and L. Cardoso, "Experimental determination of the permeability in the 
lacunar-canalicular porosity of bone," Journal of Biomechanical Engineering, vol. 131, no. 10, Article ID 101007-1, 2009.

[79] H. M. FROST, "Measurement of osteocytes per unit volume and volume components of osteocytes and canaliculae in man.," Henry Ford Hospital Medical Bulletin, vol. 8, pp. 208-211, 1960.

[80] M. A. Morris, J. A. Lopez-Curto, S. P. F. Hughes, K.-N. An, J. B. Bassingthwaighte, and P. J. Kelly, "Fluid spaces in canine bone and marrow," Microvascular Research, vol. 23, no. 2, pp. 188-200, 1982.

[81] P. Schneider, M. Meier, R. Wepf, and R. Müller, "Serial FIB/SEM imaging for quantitative $3 \mathrm{D}$ assessment of the osteocyte lacunocanalicular network," Bone, vol. 49, no. 2, pp. 304-311, 2011.

[82] D. Sharma, C. Ciani, P. A. R. Marin, J. D. Levy, S. B. Doty, and S. P. Fritton, "Alterations in the osteocyte lacunar-canalicular microenvironment due to estrogen deficiency," Bone, vol. 51, no. 3, pp. 488-497, 2012.

[83] D. Zhang, S. Weinbaum, and S. C. Cowin, "Estimates of the peak pressures in bone pore water," Journal of Biomechanical Engineering, vol. 120, no. 6, pp. 697-703, 1998.

[84] T. Lemaire, S. Naili, and A. Rémond, "Study of the influence of fibrous pericellular matrix in the cortical interstitial fluid movement with hydroelectrochemical effects.", Journal of Biomechanical Engineering, vol. 130, no. 1, p. 011001, 2008.

[85] M. L. Oyen, "Poroelastic nanoindentation responses of hydrated bone," Journal of Materials Research, vol. 23, no. 5, pp. 1307-1314, 2008. 


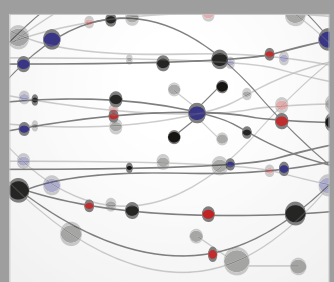

The Scientific World Journal
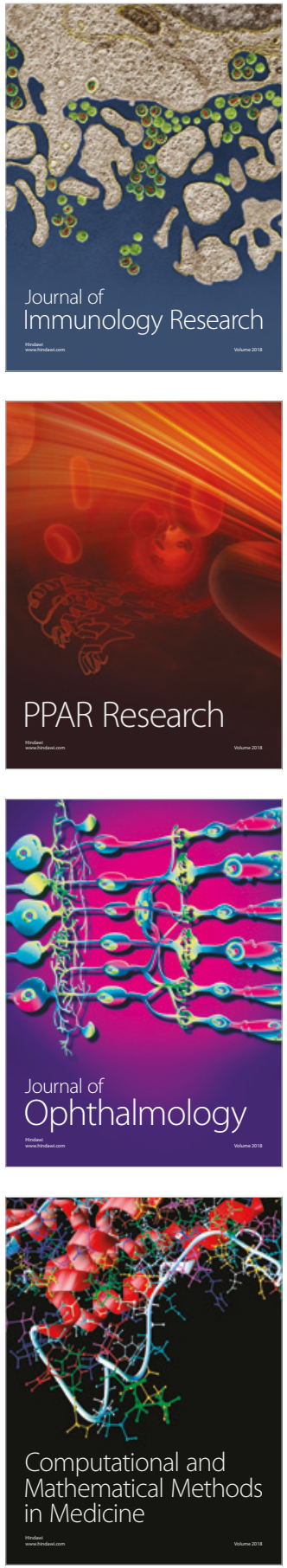

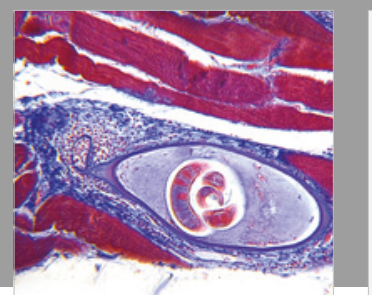

Gastroenterology Research and Practice

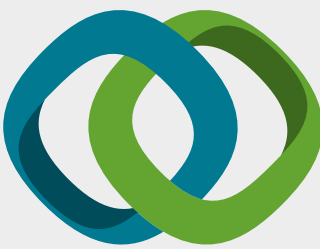

\section{Hindawi}

Submit your manuscripts at

www.hindawi.com
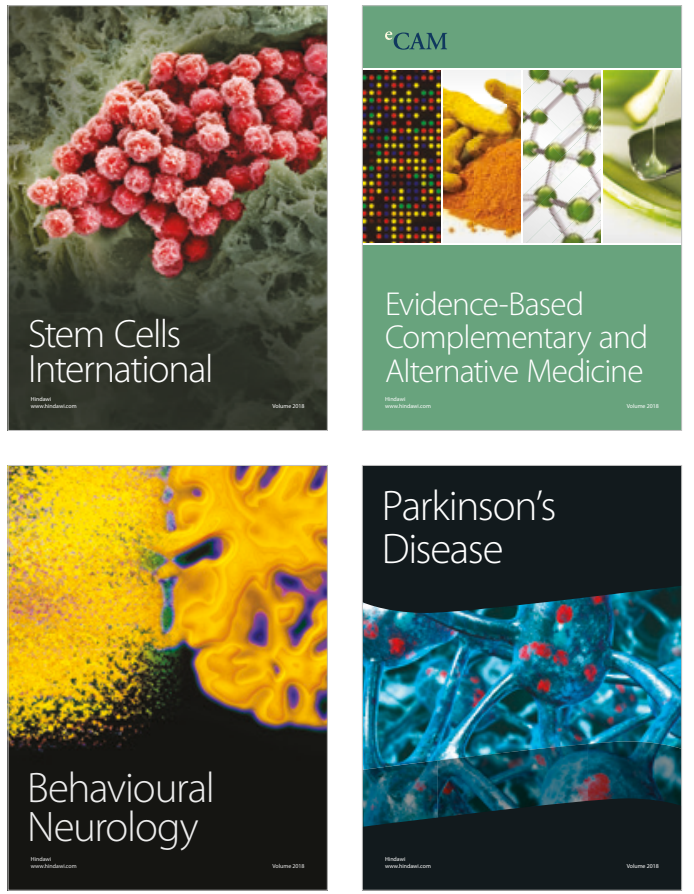

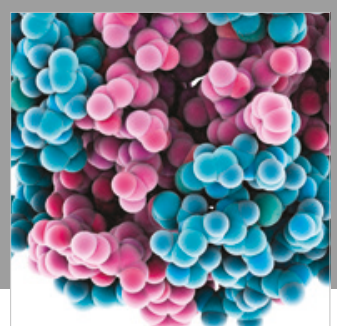

ournal of

Diabetes Research

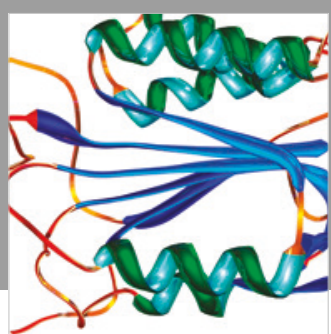

Disease Markers
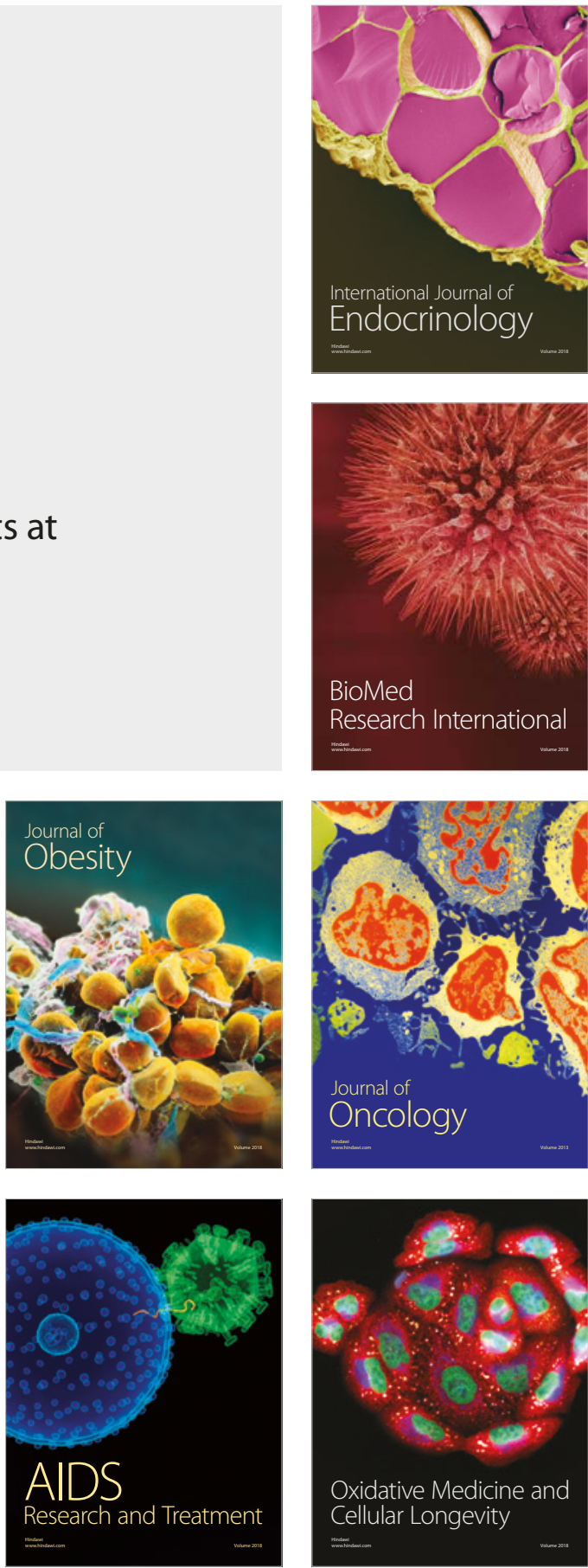